\title{
O ESTADO E AS RELAÇÕES SINDICAIS FRENTE À FORMAÇÃO PROFISSIONAL: O CASO ITALIANO NO SEGUNDO PÓS-GUERRA ${ }^{1}$
}

\author{
Pietro Causarano ${ }^{2}$ \\ Tradução: Massimo Franceschetti ${ }^{3}$
}

\section{RESUMO}

O ensaio examina a forma institucional específica com que a instrução técnica e o treinamento profissional se configuraram na Itália, condicionando de modo evidente o papel dos atores sociais. No segundo pós-guerra, depois da experiência corporativa do fascismo, as organizações sindicais iniciam a considerar a formação profissional dos trabalhadores, ao lado da alfabetização, como um fator relevante de crescimento social e civil e não só econômico. Contudo, só a partir da década de 1970 se aviam concretas estratégias nacionais e regionais neste campo.

Palavras-chave: Educação; História da Educação; formação profissional.

\section{LO STATO E LE RELAZIONI SINDACALI DI FRONTE ALLA FORMAZIONE PROFESSIONALE: IL CASO ITALIANO NEL SECONDO DOPOGUERRA}

\begin{abstract}
il saggio affronta la specifica forma istituzionale con cui l'istruzione tecnica e l'addestramento professionale si sono configurati in Italia, condizionando in modo evidente il ruolo degli attori sociali. Nel secondo dopoguerra, dopo l'esperienza corporativa del fascismo, le organizzazioni sindacali iniziano a considerare la formazione professionale dei lavoratori, accanto all'alfabetizzazione, come un fattore rilevante di crescita sociale e civile e non solo economica. Solo dagli anni '70 però si avviano concrete strategie nazionali e regionali in questo campo.
\end{abstract}

Parole chiave: Educazione; storia dell'educazione; formazione professionale

\section{Premissa}

Na indústria, o tema da formação e da instrução profissionais é bastante complexo, enquanto remete em primeira instância à relação controversa entre processos educativos e desenvolvimento econômico-produtivo e tecnológico, em analogia mais geral com a instrução técnica ${ }^{4}$. Remete também, em segunda instância, ao crescimento civil de um país e, neste, ao controle social sobre o saber, à construção da democracia e à difusão dos direitos de cidadania individuais e coletivos, bem como aos problemas relacionados à mobilidade profissional e de status ${ }^{5}$. No interior de uma sociedade dividida, este tema envolve diretamente a relação entre elaboração, difusão e controle do saber, de um lado, e a aplicação dos conhecimentos à produção, a qualificação profissional, as relações de mercado e a organização do trabalho, do outro. Uma relação que com certeza, para funcionar, deve ser focada na cooperação. Todavia, através desta, amolda-se também um aspecto relevante do conflito (e da competição) na moderna sociedade industrial, que investe a reprodução social, as identidades individuais e coletivas, as oportunidades de cada um dos indivíduos como das empresas: em síntese, o controle sobre os recursos culturais e de como este se desloca em relação à divisão do trabalho. 
Encontramo-nos, porém, em um campo da ação social onde a competição e o conflito se abrem de forma não sempre clara e evidente, mesmo sendo em vários sentidos inevitáveis. Consequentemente, os mecanismos de regulação muitas vezes não são explicitados, sobretudo no plano institucional, e muito são condicionados pela evolução econômica e organizacional da produção industrial, por um lado, e pelas escolhas políticas e orientações culturais, por outro. Nesta sede, nos limitaremos substancialmente a analizar a relação mutável entre treinamento para o trabalho e processos formativos para verificar se, e em qual medida no caso italiano, isto tenha tido um peso nas relações sindicais e industriais do segundo pós-guerra.

Encontrando-se na encruzilhada entre economia, sociedade e instituções, a mediação em torno deste conflito não explicitado - bem mais do que para a escola e a alfabetização de massa $^{6}$ - vê frequentemente um papel do Estado opaco, não direto, que deriva por longo tempo de um seu baixo perfil mais do que de um envolvimento real e ativo, fato bastante evidente na Itália até o segundo pós-guerra ${ }^{7}$. Como em outros casos, esta escassa presença reguladora não é desprovida de consequências, e quando sucessivamente se manifesta com maior força, entre a Segunda guerra mundial ou no pós-guerra, tende a enrijecer no plano institucional e administrativo - pelo menos em algumas suas componentes - um âmbito da formação que, por sua natureza, deveria estar mais pronto para receber a mudança ${ }^{8}$.

\section{Formação profissional, instrução profissional, instrução técnica}

Se isto for verdade em geral também no sentido da comparação, no caso italiano, contudo, esta complexidade é ainda mais perceptível, mas ao mesmo tempo mais incerta também, graças a outros dois elementos caracterizantes. Pelo ponto de vista dos processos históricos reais, no plano institucional, na Itália, desde a unificação nacional é bem claro o que se entende por instrução técnica, enquanto por longo tempo bem menos definida é a distinção entre esta e a instrução e a formação profissionais, de um lado, e mais ainda entre estas duas entidades no seu interior, do outro ${ }^{9}$. Ainda, pelo ponto de vista historiográfico, os estudos em matéria - se bem que não muito difusos - se concentraram assim principalmente na instrução técnica e sobre como o sistema escolar italiano tenha enfrentado, entre o século XIX e o século XX, a sua colocação na vida social e econômica e as possibilidades de empregos a ela relacionadas ${ }^{10}$. A realidade da instrução e da formação profissionais, ao contrário, ficaram substancialmente às margens, ou até excluídas, do interesse prevalecente de quem fazia pesquisa nestes campos, exatamente pela sua controversa relação com o sistema escolar ${ }^{11}$.

Ninguém, entre os estudiosos, nunca negou a permeabilidade concreta entre estes três níveis, mas é também verdade que na Itália se realizou um processo histórico de especialização, ao mesmo tempo institucional e social, que corre por toda a primeira metade do século $\mathrm{XX}$, depois de se consolidar definitivamente no período republicano, e cujas consequências se veem também na distribuição seletiva da pesquisa, que reproduziu esta separação através de aproximações parciais ao tema de investigação ${ }^{12}$. Se a instrução geral clássica, científica e técnica é definida com clareza, a profissionalização dos percursos formativos é menos evidente, ou melhor, só é evidente nas funções técnicas operacionais mais baixas e nas incumbências executivas. Este é um tema bastante vasto e complicado, mas indubitavelmente a estrutura do sistema escolar italiano, principalmente nos níveis superiores, historicamente cindiu profissionalização e estudo até os anos recentes, através da exclusão programática do estágio de trabalho dos percursos formativos também onde tivessem sido previstas atividades escolares de laboratório como na instrução técnica e profissional $^{13}$. 
Assim, o «saber fazer» foi afastado do «saber» ${ }^{14}$. A certificação dos títulos de estudo superiores (diplomas), inclusive os acadêmicos universitários, também nunca investiu na habilitação a exercer de forma competente uma profissão (sendo excluído o «aprender fazendo»), diferentemente do ofício (qualificações). Esta passagem, pelo contrário, foi adiada para a seleção operada pelas provas Estaduais para o emprego público ou para o acesso às ordens e cadastros de profissionais ou ainda à competição no mercado de trabalho particular, uma etapa de qualquer forma sucessiva à educação formal e à aquisição de saberes abstratos (ou seja, ao «aprender estudando») ${ }^{15}$. Esta cisão é ratificada de forma plástica pela lógica corporativa do fascismo para as atividades liberais, depois transmitida à Itália republicana ${ }^{16}$, mas pode valer na mesma medida em relação a profissões menores ou intermediárias, inclusive as técnicas ${ }^{17}$. Além disso, esta cisão constitui uma herança estrutural pesada de longo prazo no sistema formativo italiano, que ainda na metade da década de 80 do século passado consente a vozes respeitáveis do mundo industrial, lamentar os graves atrasos do país ${ }^{18}$. Por último, ela estruturou um credencialismo polarizado rigidamente em torno dos diplomas - saberes gerais, também de cultura técnica, orientados à profissão que se referem ao sistema escolar - e às qualificações - saberes práticos, orientados ao ofício que se referem à instrução e à formação profissionais.

A distinção aqui evocada (formação profissional, instrução profissional, instrução técnica) é, portanto, tipicamente ligada ao debate italiano e ao seu desenvolvimento industrial, ao mesmo tempo atrasado - o segundo pós-guerra e os anos 50-60 do chamado «boom econômico»- e concentrado no espaço - o centro-norte da península ${ }^{19}$. Nele, o investimento em recursos humanos, público e privado, teve, além disso, um peso relativamente escasso e foi condicionado por esta diferenciação institucional que era especular à fragmentação histórica do sistema de empresa ${ }^{20}$. Contudo, esta distinção fica bem menos compreensível para um leitor estrangeiro, principalmente se comparada com outros países onde - como norma - a eventual diferença se esgota na contraposição, ou seja, na complementariedade entre instrução técnica (teórica) e instrução profissional (de treinamento). Porém, é necessário talvez um esclarecimento terminológico preliminar que explique estas três categorias pelo ponto de vista diferencial e processual, ao menos no caso italiano, e que, além disso, explique o papel ambíguo do Estado nesta especialização institucional e administrativa que muito incidiu sobre as dinâmicas dos relacionamentos sindicais neste tópico.

\section{Formação profissional e aprendizagem: a institucionalização mal sucedida}

A formação profissional concerne prevalentemente aos cursos de treinamento ou de aperfeiçoamento (as experiências formativas de preparo voltado ao trabalho manual e executivo), em que a dimensão teórica seja bem limitada e, às vezes, completamente ausente. De um ponto de vista institucional, a formação profissional não faz parte do campo de ação do Estado e, por grande parte do século XX, nem de outras instituções públicas, mas está ancorada no mundo das relações sociais e econômicas e dos circuitos locais de solidariedade, circuitos ainda permeados em parte - principalmente na primeira metade do século passado - pela lógica da proximidade e da reciprocidade comunitária (seja no sistema assistencial, seja no paternalismo empresarial), e por uma elevada especificidade de orientações e experiências. Não é um fenômeno só italiano, mas o que impressiona para a Itália é a persistência deste modelo periférico no tempo, mesmo no segundo pós-guerra avançado, e o difícil envolvimento ativo das partes sociais, que iniciou timidamente só no segundo pósguerra $^{21}$. 
A formação profissional entrelaça a aprendizagem na empresa, mas na Itália não se reduz a isto, aliás distingue-se disto sempre mais, se bem que, em síntese, ambas certifiquem as competências adquiridas e necessárias a exercitar um cargo executivo (qualificação). À formação profissional dedicam-se uma infinidade de instituições, prevalentemente periféricas, de caráter assistencial, filantrópico, benéfico, às vezes de origem sindical ou previdencial, ou ainda mais raramente ligadas ao paternalismo empresarial, de qualquer forma caracterizadas normalmente por serem externas aos locais de trabalho e de produção efetiva, diferentemente da aprendizagem, mesmo que estas também sejam dedicadas a difundir o «saber fazer» ${ }^{22}$. Uma exceção notável é constituída pelas escolas profissionalizantes empresariais, no começo do século XX, contudo não muito difusas enquanto ligadas a realidades de forte industrialização no âmbito territorial e condicionadas pela dimensão da empresa e, assim, concentradas prevalentemente no noroeste do país (Milão, Turim, Gênova). Estas experiências, principalmente no segundo pós-guerra, são destinadas a declinar sensivelmente ${ }^{23}$.

O desenvolvimento industrial do século XX marca uma limitação dos espaços da aprendizagem informal (on the real job ou familiar, ou seja, a aprendizagem regulada pela tradição das corporações artesanais e pelas associações profissionais ou pelo trabalho camponês ${ }^{24}$. Ao mesmo tempo, isso vê uma expansão dos processos formalizados de aperfeiçoamento profissional, com sempre mais normas sobre o aspecto contratual ou organizados no âmbito institucional, dentro e fora da empresa; um fenômeno que é especular ao peso crescente da mudança técnica e tecnológica, além de organizacional, na produção durante a Grande Guerra ${ }^{25}$. Isto acontece seja em termos de adestramento ao trabalho na empresa (a aprendizagem de verdade), seja nos termos de alternância entre instrução e trabalho (mas também, com mais frequência, de alternativa) através da formação profissional. O processo se desenvolve em torno de uma espécie de «démembrement de l'éducation», um fenômeno mais geral já manifesto após a Segunda Guerra Mundial e bem esclarecido por Pierre Naville ${ }^{26}$. Isto não significa que, na Itália, formação profissional e aprendizagem, a partir da década de 30, sigam percursos diferentes, paradoxalmente no momento em que, a partir de 1928, articula-se sempre mais claramente a diferenciação institucional entre formação e instrução profissionais, com base nas competências seletivas da instrução pública, e enquanto a mesma aprendizagem pensada como treinamento na empresa obtém um reconhecimento legislativo distintivo por parte do Estado, pela primeira vez, durante a Segunda Guerra Mundial (cfr. tab. $\mathrm{n}^{\circ} 1$ em apêndice $)^{27}$.

Somente em 1938 a aprendizagem encontra um enquadramento legislativo ao qual a realidade contratual possa se referir, quando, pela primeira vez, individua-se a idade mínima em 14 anos, vínculo de tutela que chega só quinze anos depois de que a obrigação escolar tinha sido elevada à mesma idade e quatro anos depois da lei fascista sobre o trabalho dos menores, um claro sinal de quanto fosse difícil e controversa a questão, pressionada entre necessidades econômicas e aspirações de civilização (cfr. tab. $\mathrm{n}^{\circ} 2 \mathrm{em}$ apêndice $)^{28}$. O Código Civil de 1942 regula só a figura do aprendiz (direitos e deveres), não a instituição da aprendizagem como tal. A nova legislação da Itália pós-fascista e republicana, outrossim, consegue disciplinar a aprendizagem em empresa de forma mais coerente (L. 25/1955), afirmando pela primeira vez explicitamente a obrigação para o empregador de fornecer também um ensino teórico complementar (arts. 16-19), obrigação na maior parte dos casos descumprida, como reclamado pela polêmica sindical ${ }^{29}$. As isenções previstas pelo regulamento vigente em 1956, em particular para os aprendizes em posse de qualificações profissionais conseguidas em estudos secundários ou de formação extraescolar, ou em posse de diploma de ensino complementar profissionalizante (pós-fundamental), confirmam definitivamente a divergência entre os dois momentos de capacitação ao trabalho, interno ou 
externo à empresa, aprendizagem e formação profissional (e, com maior razão, instrução profissional escolar, assim como definida ao final da década de 1930).

\section{Instrução profissional e instrução técnica: a fraca institucionalização}

A instrução profissional, de um ponto de vista teórico geral, enquanto categoria não seria muito diversa da formação profissional, senão por uma maior fração de formação técnica teórica específica, para uma definição mais clara e estável dos níveis de classificação da qualificação do trabalho, e para uma estrutura organizacional mais definida da oferta formativa. Enquanto tais, normalmente as duas categorias de formação e instrução profissionais, de fato, não são distintas rigorosamente em outras realidades nacionais e, também na Itália, por longo tempo são usadas impreterivelmente como sinônimos, distinguindo-se da aprendizagem de verdade. Contudo, na Itália a instrução profissional no período da década de 10 à década de 30 do século $\mathrm{XX}$ - se afasta aos poucos, no âmbito institucional e organizacional, daqueles circuitos locais ou corporativos que a haviam igualado à formação profissional ainda na passagem do século. A partir da idade giolittiana e depois com o fascismo, frente aos primeiros passos da industrialização italiana, assistimos - mesmo entre ambiguidades e mudanças de ideias - a uma sorte de absorção progressiva da instrução profissional na esfera de influência do Estado central (uma das formas assumidas pelo «central involvment» novecentista) e da sua ação de regulação social ${ }^{30}$.

Com o fascismo, entre 1928 e 1938, a instrução profissional se torna sempre mais escola e, assim, universalizando-se, se afasta da acentuada especificidade da formação profissional e, com maior razão, da aprendizagem (cfr. tab. $\mathrm{n}^{\circ} 1 \mathrm{em}$ apêndice). Neste processo - pelo ponto de vista do credencialismo no mercado de trabalho - a instrução profissional se aproxima de forma minoritária à instrução técnica, campo próprio de uma profissionalização do trabalho mais precisa, nítida, em nível nacional e, como tal, garantida diretamente pelo Estado desde a unidade italiana. Isto é, define qualificações executivas mais elevadas do trabalho genérico e melhor estatuídas da formação profissional, que, contudo, se colocam abaixo das figuras técnicas intermediárias ${ }^{31}$. Este processo distintivo é lento e cheio de ambiguidades também terminológicas se, ainda no segundo pós-guerra, a Constituição republicana de 1948 - ao prever a autonomia regional - entrega aos novos níveis institucionais de governo territorial, às regiões, a competência direta no campo da «instrução artesanal e profissional» (art. 117). A Carta, contudo, entende circunscrever desta forma só a formação profissional extraescolar e não as escolas técnicas que, desde o final da década de 20, acabaram definitivamente fazendo parte da esfera da ação estatal e da instrução pública.

A instrução técnica, de primeiro e segundo grau, mesmo marcada também por árduas vicissitudes normativas e regulamentares principalmente nas décadas de 20 e 30 em seguida à reforma fascista do ministro Giovanni Gentile ${ }^{32}$, mantém sempre a sua originária caracterização escolar ancorada na educação nacional, salvo um breve parêntese na década de $20^{33}$. Esta se configura como uma espécie de câmara de compensação ao interior da lógica dual fortemente divaricada do sistema formativo italiano, no plano social e cultural ${ }^{34}$, uma polarização formativa que, por outro lado, é tipica de muitos países europeus na primeira parte do século XX frente à industrialização. Por un lado, a instrução média de caráter geral e abstrato, acadêmico-liceal, que conduz à universidade e em que o modelo gentiliano privilegia a instrução clássica; por outro, a formação diretamente adestradora, escolar e extraescolar, que dá acesso, em um tempo breve, ao trabalho executivo e manual qualificado e semiqualificado; a instrução média técnica se coloca no meio, está culturalmente subordinada à instrução geral mas, situa-se em posição superior, em termos de status e de 
funções unitariamente definidas, ao macrocosmo desarticulado da instrução e, principalmente, da formação profissionais ${ }^{35}$.

\section{Uma distinção resistente no tempo}

Apesar de a Constituição republicana - como dito antes - prever em 1948 a instituição das regiões e, naquele contexto de autonomia crescente do governo local, previsse de confiar-lhes as competências em matéria de formação profissional, na realidade o sistema de governo regional será ativado efetivamente de forma completa somente em 1970. O processo de transferência às regiões dos percursos profissionalizantes formativos e adestradores extraescolares se encaminha com o DPR 10/1972. O percurso normativo e organizacional da regionalização em matéria será terminado só pela L. 845/1978, que permitirá uma primeira ligação com a aprendizagem (cfr. tab. $\mathrm{n}^{\circ} 1 \mathrm{em}$ apêndice). Só nos primeiros anos da década de 80 e depois de trinta anos desde a Constituição republicana, portanto, iniciarão realmente seja uma política regional de programação neste campo, seja a definição de sistemas de relações sindicais a esta escala intermediária entre Estado nacional e governo local ${ }^{36}$. Além disso, só então comparecerão sistematicamente outros atores institucionais e sociais na cena, graças a uma atenção nova e crescente à formação dos recursos humanos e ao lifelong learning, que acompanharão as entidades de emanação sindical, os antigos circuitos assistenciais e, principalmente, substituirão as estruturas corporativas herança do fascismo, suprimidas somente em 1978. A dimensão local, na Itália, fica de qualquer forma predominante se bem que redefinida ao interior do planejamento em escala regional e, sucessivamente, em relação às políticas sociais e do trabalho nacionais e depois comunitárias em nível europeu entre as décadas de 80 e $90^{37}$.

A partição histórica que distingue instrução e formação profissionais, a despeito de todas as mudanças institucionais, sociais e econômicas do tumultuoso pós-guerra, funciona assim até anos recentes, bem além da "grande transformação» da mesma sociedade industrial. Nos primeiros anos sucessivos à regionalização, aliás, ela amplifica inevitavelmente a divaricação entre a instrução profissional considerada como escola profissional estatal e a formação profissional regional considerada como experiência rigorosamente extraescolar (mas não necessariamente on the real job como a aprendizagem $)^{38}$. Na década de 90 , contudo, emergem estratégias sistémicas sempre mais tendentes à coordenação e à integração no interior da lógica europeia, mostrando uma convergência que aproxima a Itália de outras experiências comunitárias ${ }^{39}$.

Hoje algo está mudando após a reforma orgânica da instrução média prevista pela lei Moratti (L. 53/2003), que regulamenta a alternância escola-trabalho (art. 4), novidade absoluta para o sistema formativo italiano: por um lado, esta introduz o treinamento externo e profissionalizante perto do estudo teórico ou da prática dos laboratórios intra mœnia; de outro modo, introduz a coordenação, na formação e instrução profissionais, entre os dois canais que se separaram desde a década de 30, através da nova obrigação formativa até 18 anos, prevista pela primeira vez pela L. 144/1999 (art. 68), a ser cumprida dentro do sistema unitário da instrução e formação profissionais, individuado sempre pela L. 53/2003 (art. 2, parágrafos $\mathrm{de} \mathrm{h})^{40}$.

Um quadro normativo e regulamentar assim articulado e complexo, ainda mais substancialmente estável no tempo até anos recentes, condicionou inevitavelmente as modalidades de regulação das relações sindicais neste campo. A excessiva fragmentação e especificidade das experiências formativas e a frequente particularidade local ou corporativa das modalidades de intervenção impediram por longo tempo que os sujeitos sociais se interessassem sistematicamente pela questão e segundo perspectivas não ocasionais. E é esta 
uma das heranças mais pesadas do fascismo, à qual as primeiras intervenções republicanas, entre 1947 e 1949, orientadas à educação popular, à alfabetização, à luta ao desemprego, oferecem só um tímido paliativo no plano da profissionalização (tab. $n^{\circ} 1$ em apêndice) ${ }^{41}$. De outra forma, o processo de absorção por parte do Estado da instrução profissional, aviado na década de 30 e não questionado pela regionalização da década de 70 , comporta uma substancial delegação à instrução pública desta matéria por parte dos atores sociais, enquanto confirma a marginalidade e secundariedade da formação profissional, novamente remetida aos circuitos locais e periféricos na atuação operacional da atividade formativa ${ }^{42}$.

\section{As relações sindicais entre local e nacional}

Confindustria, a principal organização de representação dos empregadores privados, organiza seu primeiro congresso público sobre estes temas só em $1959^{43}$. As organizações sindicais, principalmente a CGIL, por longo tempo atribuíram à alfabetização fundamental a solução da questão, considerando que ainda no começo da década de 50 os três quartos dos meninos com idade de obrigação escolar não terminavam a nona série do ensino fundamental, inclusive o ensino profissionalizante, e que, assim, o problema em prosseguir eventualmente na instrução e formação profissionais era totalmente virtual ${ }^{44}$. Nas entrevistas e nas análises ligadas às primeiras indagações parlamentares da Itália republicana sobre a questão social (as sobre a miséria e o desemprego de 1953, a sobre as condições de trabalho de 1959), a formação profissional resulta assim ainda totalmente secundária ou ausente na atenção dos atores sociais e, com frequência, também dos especialistas ${ }^{45}$. Afinal, naqueles anos a Itália é um país em que o impacto social da produção industrial ainda está se afirmando e em que, por outro lado, os percursos da alfabetização, principalmente no campo e no Sul, estão sempre claramente com atraso em relação às outras realidades europeias ${ }^{46}$.

Para o sindicato maioritário, por toda a década de 50, a prioridade é escolarizar, alfabetizar e instruir o povo ainda antes que profissionalizá-lo. Em todo caso, a CGIL aponta para aprendizagem de empresa, por sua natureza em teoria mais funcional à evolução social de um país ainda percebido - erradamente - como atrasado. A promulgação da nova lei em 1955 ocorre paradoxalmente quando o instituto da aprendizagem está declinando visivelmente junto com as perspectivas de «carreira operária », ao menos na grande produção de série ${ }^{47}$. Ao contrário, mesmo ao longo da década de 50 , a transformação industrial, a plena afirmação de novos modelos organizacionais (o scientific management) e de classificação do trabalho (a job evaluation), a maciça penetração do taylor-fordismo em alguns setores produtivos principais, justificam o deslocamento definitivo ao externo da empresa, em chave compensatória, da formação e da capacitação para o trabalho, sem que, contudo, o sindicato seja preparado para uma perspectiva cooperativa sobre a formação profissional $^{48}$.

Até os governos de Centro-esquerda da década de 60, a questão não é substancialmente enfrentada pelo sindicato principal, a CGIL, apesar de a contemporânea crise de representação nas fábricas abra um debate lacerante sobre as inovações tecnológicas e organizacionais e sobre as modalidades novas do trabalho industrial que colocam em discussão as formas históricas da classificação e da qualificação operária ${ }^{49}$. Em contraposição à CGIL, este tema começa ser objeto das relações sindicais na indústria pública (química e siderúrgica) e encontra a disponibilidade negocial das outras duas confederações sindicais, a católica e a reformista ${ }^{50}$.

O caráter fortemente centralizado das relações industriais e da contratação, desde a década de 50 até a segunda metade da década de 60 , em todo caso penaliza fortemente a possibilidade de que o tema da formação profissional seja incluído no campo da negociação, 
vista a sua dispersão. Apesar das referências rituais à aprendizagem, a ausência de contratação descentralizada até a primeira metade da década de 60 destaca, entre outros, a falta de atenção substancial a este tema, com exceção de alguma forma de apoio assistencial à escolarização seja dos menores que dos adultos. Em particular, o contrato nacional dos metalúrgicos e siderúrgicos é silencioso sobre estes temas até $1968^{51}$. Uma reviravolta, se bem que provisória, ocorre só depois da quebra de 1969 (o chamado «Outono quente»).

Frente à fase de mais alta conflitualidade operária do pós-guerra, da contestação das relações de força nas empresas e da deslegitimação da organização estabelecida do trabalho, entre as décadas de 60 e 70 desenvolve-se uma poderosa atividade de negociação descentralizada em nível de empresa que investe uma pluralidade de temas historicamente marginais, entre os quais também as questões formativas e da recuperação escolar, bem menos as da profissionalização ${ }^{52}$. Os contratos nacionais da indústria em 1973-74 (mecânicos, químicos, têxteis), primeiro, conseguem duas novas instituições - o enquadramento único operários-empregados (classificação única) e o montante horário retribuído para o direito de estudo (as chamadas «150 horas») - que giram, ambas, em torno das oportunidades de mobilidade profissional, horizontal e vertical, focadas na ideia de «polivalência» e de «profissionalidade» e não mais na distinção entre profissão (diploma) e ofício (qualificação) ${ }^{53}$.

As dificuldades assinaladas desde a década de 60 se confirmam também na segunda metade da década de 70, a da grande crise econômica e da transformação incipiente da sociedade industrial, após a censura política e social de 1968-69 e a temporada contratual da metade da década. Na cultura sindical, se bem que em presença de uma forte descentralização contratual ao menos nas grandes empresas, fica a polarização entre formação geral e perspectivas profissionalizantes e adestradoras para o trabalho industrial. O sindicato não consegue ler em uma nova perspectiva os problemas da mobilidade social, se bem que a organização do trabalho e as expectativas individuais e coletivas a respeito e a respeito da formação estejam mudando ${ }^{54}$. Em particular, a iniciativa sindical - sempre mais em dificuldade pela crise econômica - não consegue intervir quanto ao nexo institucional, que já vimos ser frágil, entre instrução profissional escolar, formação e treinamento extraescolares e aprendizagem, tanto que a ação contratual daqueles anos não colhe com plenitude a novidade da mesma regionalização nem utiliza nesta direção as «150 horas » 55 . A ação sindical unitária, na Itália, limita-se naqueles anos a perseguir a tradicional palavra de ordem da democratização nas oportunidades formativas, delegando ainda, em substância, a questão profissional a velhos e novos sistemas institucionais e administrativos (ensino técnico e profissional, formação profissional regional), mas em uma leitura que fica socialmente compensatória e pouco atenta às políticas ativas do trabalho ${ }^{56}$. Não é acaso que a experiência das " 150 horas » para o direito de estudo perca bastante impulso inovador já no final da década e depois, nos anos seguintes, desloque seu fulcro para fora dos setores industriais, em direção de serviços e emprego público ${ }^{57}$.

A situação da contratação em matéria de formação profissional e de recursos humanos não melhora nos anos 80-90 (e também depois), mesmo frente à transformação radical vinda, no entanto, a tumultuar o sistema industrial. Nem mesmo o completo aparato das políticas regionais e comunitárias em matéria de lifelong learning desloca os termos da questão. A dificil articulação territorial e empresarial da contratação descentralizada e, em particular, a fragilidade histórica da negociação em nível de empresa, impedem que, de fato, na Itália, nos ocupemos com efeito deste tema e, quando isso acontece, refere-se prevalentemente às médias e grandes empresas com mais de 250 empregados, ou seja, à parte minoritária do sistema. No total das empresas italianas, os contratos empresariais que enfrentam o tema da formação nos últimos vinte anos do século XX colocam-se em 
percentuais irrisórios (uma média de $6 \%$ do total) e, com frequência, a referência é meramente ritual e rotineira ${ }^{58}$. No mesmo período e praticamente até hoje, contudo, nada substancial intervém a modificar a estrutura da instrução técnica e profissional que continua aquela que se afirmou no segundo pós-guerra, enquanto a formação profissional permanece na realidade acessória e pouco incisiva apesar da regionalização e dos crescentes recursos disponíveis.

\section{Algumas observações conclusivas sobre continuidade e cesuras}

Como já dito no começo, o sistema formativo italiano, historicamente, tem sempre privilegiado a formação geral, em particular da área de humanas, com prejuízo daquela científica e técnica e, com maior razão, daquela profissional. Isso não exclui que, historicamente, tenham tido passagens decisivas não só no debate cultural e pedagógico (por ex. A discussão sobre ensino fundamental, ensino técnico e ensino popular no começo do século $\mathrm{XX}$, a discussão sobre o ensino fundamental único e sobre a reforma do ensino secundário médio nas décadas de 50-60, o debate sobre a reforma geral do sistema escolar na década de 70 ${ }^{59}$, mas também no deslocamento dos atores e na definição dos instrumentos normativos e organizacionais, que marcam uma atividade de reforma - ainda que em ondas - neste campo (cfr. tab. $\mathrm{n}^{\mathrm{o}} 1$ em apêndice).

Os ministérios econômicos em idade giolittiana intervêm de forma sempre mais evidente a racionalizar em via administrativa o campo de ação social surgido na periferia do sistema de governo local, em que as subculturas políticas de oposição, a católica e a socialista, experimentam novos modelos municipais de intervenção para enfrentar as questões levantadas pela primeira industrialização de uma parte do país ${ }^{60}$. Uma passagem decisiva se realiza, depois da Grande guerra, com o regime fascista e seu dirigismo corporativo. Além do parêntese marcadamente humanístico da reforma Gentile, os anos que abrangem de 1928 até a guerra decretam a separação entre a instrução profissional enquanto escola e a formação profissional enquanto experiência extraescolar, no interior de uma profunda reorganização do setor que, de fato, resiste desde 1962, no que concerne ao ensino profissionalizante post-fundamental, e até à regionalização, quanto à instrução técnica e profissional Estadual (ensino médio). O que acontece no imediato pós-guerra republicano é pouco, e é amplamente sobrepujado pelas profundas transformações sociais e econômicas que caracterizam a passagem à condição de moderna grande nação industrial, entre as décadas de 50 e 60. Só para fazer um exemplo, os primeiros cursos noturnos de instrução técnica para adultos trabalhadores só são ativados entre 1964 e 1966 (cfr. tab. nº 1 em apêndice).

A cesura mais relevante do período republicano, antes da regionalização, é significativamente constituída por uma intervenção propriamente de política escolar, a instituição do ensino fundamental único em 1962, que - criando um percurso de instrução geral comum até o cumprimento da obrigação escolar - leva à abolição do ensino secundário profissionalizante, garantindo finalmente uma coerência entre oferta formativa e cumprimento da obrigação escolar. Abre-se, assim, graças ao maior bem-estar difuso, a oportunidade de prosseguir os estudos além do limite escolar, de que se avantaja a instrução técnica e profissional escolar ${ }^{61}$. Pelo restante, muda bem pouco, com a exceção que, no período dos governos de Centro-esquerda (década de 60), em uma conjuntura política mais distintamente pro labour que no passado e em conexão com a escolarização de massa incipiente, cresce o investimento estatal na promoção do sistema de instrução profissional estatal e em alguns setores da formação profissional ${ }^{62}$. É significativo que a contraposição entre acesso à cultura geral e treinamento continue, contudo, a polarizar o debate naqueles 
anos. Esta constituirá também a referência sucessiva, quando se porá - em relação às temáticas formativas - o problema de "uma intervenção consciente sobre a divisão do trabalho $»^{63}$.

Esta aproximação é encontrada seja na esquerda política que naquela sindical ${ }^{64} \mathrm{e}$ tende a excluir ou a reenviar, através do modelo da educação politécnica, o tema da profissionalização na formação, como em geral todas as questões ligadas à didática ${ }^{65}$. A aspiração à « polivalência » (seja formativa que profissional), conexa à categoria emergente de "profissionalidade " ${ }^{66}$, reenvia a questão de novo à escola e não consegue reincluir plenamente no interior das estratégias sindicais a formação profissional do trabalho industrial ${ }^{67}$.

Em 1969, ano da revolta operária, constitui neste campo da ação sindical, como para outros, uma verdadeira demarcação e abre as portas à regionalização do sistema institucional da década de 70 e à plena afirmação da ideia de direito de estudo contraposta à assistência escolar. Revertendo-se momentaneamente as relações de força na empresa e sendo contestada uma estrutura da reprodução social geral que condiciona as expectativas individuais, emerge então a que é definida uma verdadeira « reivindicação formativa » que se coliga à transição contemporânea da centralidade social do ensino àquela da aprendizagem, muito debatida na Itália também no plano pedagógico e didático, e da qual as " 150 horas » são o fruto mais importante ${ }^{68}$. Mas a profissionalização dos percursos formativos permanece às margens deste debate ainda por muito tempo.

\title{
Lo Stato e le relazioni sindacali di fronte alla formazione professionale: il caso italiano nel secondo dopoguerra
}

\author{
(Pietro Causarano - Università degli Studi di Firenze)
}

Abstract: il saggio affronta la specifica forma istituzionale con cui l'istruzione tecnica e l'addestramento professionale si sono configurati in Italia, condizionando in modo evidente il ruolo degli attori sociali. Nel secondo dopoguerra, dopo l'esperienza corporativa del fascismo, le organizzazioni sindacali iniziano a considerare la formazione professionale dei lavoratori, accanto all'alfabetizzazione, come un fattore rilevante di crescita sociale e civile e non solo economica. Solo dagli anni '70 però si avviano concrete strategie nazionali e regionali in questo campo.

\section{Premessa}

Nell'industria, il tema della formazione e dell'istruzione professionali è assai complesso, in quanto rimanda in prima battuta al rapporto controverso fra processi educativi e sviluppo economico-produttivo e tecnologico, in analogia più generale con l'istruzione tecnica. Rimanda anche, in seconda battuta, alla crescita civile di un paese e, in essa, al controllo sociale sul sapere, alla costruzione della democrazia e alla diffusione dei diritti di cittadinanza individuali e collettivi, come anche ai problemi connessi alla mobilità professionale e di status. All'interno di una società divisa, questo tema coinvolge direttamente la relazione fra elaborazione, diffusione e controllo del sapere, da una parte, e l'applicazione delle conoscenze alla produzione, la qualificazione professionale, i rapporti di mercato e l'organizzazione del lavoro, dall'altra. Una relazione che certamente, per 
funzionare, deve essere centrata sulla cooperazione. Attraverso essa, tuttavia prende anche forma un aspetto rilevante del conflitto (e della competizione) nella moderna società industriale, che investe la riproduzione sociale, le identità individuali e collettive, le opportunità dei singoli individui come delle imprese: in sintesi, il controllo sulle risorse culturali e di come esso si disloca nei confronti della divisione del lavoro.

Ci troviamo però in un campo dell'azione sociale dove la competizione e il conflitto si dispiegano in maniera non sempre chiara ed evidente, pur essendo per molti versi inevitabili. Conseguentemente i meccanismi di regolazione spesso non sono esplicitati, soprattutto sul piano istituzionale, e molto sono condizionati dall'evoluzione economica e organizzativa della produzione industriale, da una parte, e dalle scelte politiche e dagli orientamenti culturali, dall'altra. In questa sede, ci limiteremo sostanzialmente ad analizzare il rapporto mutevole fra addestramento al lavoro e processi formativi per verificare se e in quale misura nel caso italiano esso abbia avuto un peso nelle relazioni sindacali e industriali del secondo dopoguerra.

Trovandosi al crocevia fra economia, società e istituzioni, la mediazione attorno a questo conflitto non esplicitato - assai più che per la scuola e l'alfabetizzazione di massa vede spesso un ruolo dello Stato opaco, non diretto, che deriva per lungo tempo da un suo basso profilo piuttosto che da un reale e attivo coinvolgimento, fatto assai evidente in Italia fino al secondo dopoguerra. Come in altri casi, questa scarsa presenza regolatrice non è priva di conseguenze e quando poi si manifesta con maggiore forza, a cavallo della Seconda guerra mondiale o nel dopoguerra, tende ad irrigidire sul piano istituzionale e amministrativo almeno in alcune sue componenti - un ambito della formazione che per sua natura dovrebbe essere più pronto a recepire il mutamento.

\section{Formazione professionale, istruzione professionale, istruzione tecnica}

Se questo è vero in generale anche in chiave comparata, nel caso italiano tuttavia questa complessità è ancor più percepibile, ma insieme anche più incerta, grazie a due altri elementi caratterizzanti. Dal punto di vista dei reali processi storici, sul piano istituzionale in Italia fin dall'unificazione nazionale è ben chiaro cosa si intenda per istruzione tecnica, mentre per lungo tempo assai meno definita è la distinzione fra essa e l'istruzione e la formazione professionali, da una parte, e soprattutto fra queste due entità al loro interno, dall'altra. Dal punto di vista storiografico, inoltre, gli studi in materia - ancorché non molto diffusi - si sono così concentrati prevalentemente sull'istruzione tecnica e su come il sistema scolastico italiano abbia affrontato, fra ' 800 e ' 900 , la sua collocazione nella vita sociale e economica e gli sbocchi occupazionali ad essa correlati. La realtà dell'istruzione e della formazione professionali, invece, è sostanzialmente rimasta ai margini, se non addirittura esclusa, dall'interesse prevalente di chi faceva ricerca in questi campi, proprio per la sua controversa relazione con il sistema scolastico.

Nessuno, fra gli studiosi, ha mai negato la concreta permeabilità fra questi tre livelli, ma è anche vero che in Italia si è realizzato un processo storico di specializzazione, insieme istituzionale e sociale, che corre per tutta la prima metà del '900, poi consolidatosi definitivamente nel periodo repubblicano, e le cui conseguenze si vedono anche nella distribuzione selettiva della ricerca, che ha riprodotto questa separazione attraverso approcci parziali al tema d'indagine. Se l'istruzione generale classica, scientifica e tecnica è chiaramente definita, la professionalizzazione dei percorsi formativi è meno evidente, o meglio è evidente solo nelle funzioni tecniche operative più basse e nelle mansioni esecutive. E' questo un tema assai vasto e complicato, ma indubbiamente la struttura del sistema scolastico italiano, soprattutto ai livelli superiori, ha storicamente scisso professionalizzazione e studio fino ad anni recenti, attraverso l'esclusione programmatica 
del tirocinio lavorativo dai percorsi formativi anche là dove fossero state previste attività scolastiche di laboratorio come nell'istruzione tecnica e professionale.

Il «saper fare» è stato così allontanato dal «sapere». La certificazione dei titoli di studio superiori (diplomi), compresi quelli accademici universitari, inoltre non ha mai investito l'abilitazione ad esercitare in maniera competente una professione (essendo escluso l'«imparare facendo»), a differenza del mestiere (qualifiche). Questo passaggio invece è stato rinviato alla selezione operata dagli esami di Stato per il pubblico impiego o per l'accesso agli ordini e albi professionali oppure alla competizione del mercato del lavoro privato, un passaggio comunque successivo alla formazione formale e all'acquisizione di saperi astratti (cioè all' «imparar studiando»). Questa scissione è sancita in maniera plastica dalla logica corporativa del fascismo per le attività liberali, poi trasmessa all'Italia repubblicana, ma può valere nella stessa misura rispetto a professioni minori o intermedie, comprese quelle tecniche. Questa scissione costituisce inoltre una pesante eredità strutturale di lungo periodo nel sistema formativo italiano, che ancora alla metà degli anni ' 80 del secolo scorso consente a voci autorevoli del mondo industriale di lamentare i gravi ritardi del paese. Infine essa ha strutturato un credenzialismo rigidamente polarizzato attorno ai diplomi saperi generali, anche di cultura tecnica, orientati alla professione e facenti riferimento al sistema scolastico - e alle qualifiche - saperi pratici, orientati al mestiere e facenti riferimento all'istruzione e alla formazione professionali.

La distinzione qui evocata (formazione professionale, istruzione professionale, istruzione tecnica) è dunque tipicamente legata al dibattito italiano e al suo sviluppo industriale, insieme ritardato nel tempo - il secondo dopoguerra e gli anni '50-'60 del cosiddetto «boom economico» - e concentrato nello spazio - il centro-nord della penisola. In esso, l'investimento in risorse umane, pubblico e privato, ha inoltre avuto un peso relativamente scarso ed è stato condizionato da questa differenziazione istituzionale che era speculare alla frammentazione storica del sistema d'impresa. Questa distinzione risulta però assai meno comprensibile per un lettore straniero, soprattutto se raffrontata con altri paesi dove - di norma - la eventuale differenza si esaurisce nella contrapposizione, ovvero nella complementarietà, fra istruzione tecnica (teorica) e istruzione professionale (addestrativa). E' quindi forse necessaria una preliminare chiarificazione terminologica che spieghi in chiave differenziale e processuale queste tre categorie, almeno per il caso italiano, e che spieghi inoltre il ruolo ambiguo dello Stato in questa specializzazione istituzionale e amministrativa che molto ha inciso sulle dinamiche delle relazioni sindacali in questa materia.

\section{Formazione professionale e apprendistato: la mancata istituzionalizzazione}

La formazione professionale riguarda prevalentemente i corsi di addestramento o di perfezionamento (le esperienze formative di preparazione diretta al lavoro manuale ed esecutivo), in cui la dimensione teorica risulti assai limitata e, talvolta, completamente assente. Da un punto di vista istituzionale, la formazione professionale non rientra nel campo d'azione dello Stato e, per larga parte del '900, neppure di altre istituzioni pubbliche, ma resta ancorata al mondo delle relazioni sociali ed economiche e dei circuiti locali di solidarietà, circuiti ancora in parte permeati - soprattutto nella prima metà del secolo scorso - dalla logica della prossimità e della reciprocità comunitaria (sia nel sistema assistenziale sia nel paternalismo aziendale) e da una elevata specificità di indirizzi ed esperienze. Non è un fenomeno solo italiano, ma ciò che colpisce per l'Italia è la persistenza di questo modello periferico nel tempo, anche nel secondo dopoguerra inoltrato, e il difficile coinvolgimento attivo delle parti sociali, cominciato timidamente solo nel secondo dopoguerra. 
La formazione professionale incrocia l'apprendistato in impresa, ma in Italia non si riduce ad esso, anzi se ne distingue sempre più, benché ambedue in fondo certifichino le competenze acquisite e necessarie ad esercitare una mansione esecutiva (qualifica). Alla formazione professionale si dedicano una miriade di istituzioni, prevalentemente periferiche, a carattere assistenziale, filantropico, benefico, talvolta di origine sindacale o mutualistica oppure anche più raramente legate al paternalismo aziendale, comunque caratterizzate di norma dall'essere esterne ai luoghi di lavoro e di produzione effettiva, a differenza dell'apprendistato, seppur dedite anch'esse a diffondere il «saper fare». Un'eccezione rilevante è costituita dalle scuole professionali aziendali, all'inizio del '900 tuttavia non molto diffuse essendo legate a realtà di forte industrializzazione sul piano territoriale e condizionate dal dimensionamento d'impresa e quindi concentrate prevalentemente nel nord-ovest del paese (Milano, Torino, Genova). Queste esperienze, soprattutto nel secondo dopoguerra, sono destinate a declinare vistosamente.

Lo sviluppo industriale del XX secolo segna un restringimento degli spazi dell'apprendistato informale (on the real job o familiare, l'apprendistato regolato cioè dalla tradizione delle corporazioni artigiane e delle associazioni di mestiere o dal lavoro contadino). Nello stesso tempo esso vede un'espansione dei processi formalizzati di perfezionamento professionale, sempre più normati sul piano contrattuale o organizzati sul piano istituzionale, dentro e fuori l'azienda; un fenomeno che è speculare al crescente peso del cambiamento tecnico e tecnologico, oltre che organizzativo, nella produzione a cavallo della Grande guerra. Questo avviene sia nei termini di addestramento al lavoro nell'impresa (l'apprendistato vero e proprio) sia nei termini di alternanza fra istruzione e lavoro (ma anche più frequentemente di alternativa) attraverso la formazione professionale. Il processo avviene attorno ad una specie di «démembrement de l'éducation», un fenomeno più generale ormai dispiegato all'indomani della Seconda guerra mondiale e ben evidenziato da Pierre Naville. Ciò non toglie che, in Italia, formazione professionale e apprendistato, a partire dagli anni '30, seguano strade diverse, paradossalmente nel momento in cui, dal 1928, si articola sempre più chiaramente la differenziazione istituzionale fra formazione e istruzione professionali, in base alle competenze selettive della pubblica istruzione, e nel mentre lo stesso apprendistato inteso come addestramento in impresa ottiene un riconoscimento legislativo distintivo da parte dello Stato, per la prima volta, a cavallo della Seconda guerra mondiale (cfr. tab. n. 1 in appendice).

L'apprendistato trova solo nel 1938 un inquadramento legislativo cui la realtà contrattuale possa far riferimento, quando per la prima volta si individua l'età minima a 14 anni, vincolo a tutela che arriva ben quindici anni dopo che l'obbligo scolastico era stato elevato alla medesima età e quattro anni dopo la legge fascista sul lavoro minorile, un chiaro segnale di quanto fosse difficile e controversa la questione, stretta fra necessità economiche e aspirazioni di civiltà (cfr. tab. 2 in appendice). Il Codice civile del 1942 regola solo la figura dell'apprendista (diritti e doveri), non l'istituto dell'apprendistato in quanto tale. La nuova legislazione dell'Italia post-fascista e repubblicana, poi, arriva a disciplinare l'apprendistato in impresa in maniera più coerente (L. 25/1955), affermando per la prima volta esplicitamente l'obbligo per il datore di lavoro di fornire anche un insegnamento teorico complementare (art. 16-19), obbligo nella maggior parte dei casi disatteso come lamentato dalla polemica sindacale. Le esenzioni previste dal regolamento attuativo del 1956 , in particolare per gli apprendisti in possesso di qualifiche professionali ottenute in studi secondari o di formazione extra-scolastica oppure in possesso della licenza della scuola complementare di avviamento al lavoro (post-elementare), confermano definitivamente la divaricazione fra $\mathrm{i}$ due momenti addestrativi al lavoro, interno o esterno all'impresa, 
apprendistato e formazione professionale (e a maggior ragione istruzione professionale scolastica, così come definita alla fine degli anni '30).

\section{Istruzione professionale e istruzione tecnica: la debole istituzionalizzazione}

L'istruzione professionale, da un punto vista teorico generale, come categoria non sarebbe troppo diversa dalla formazione professionale, se non per una maggiore quota-parte di formazione tecnica teorica specifica, per una più chiara e stabile definizione dei livelli di classificazione della qualificazione del lavoro e per una struttura organizzativa più definita dell'offerta formativa. Come tali, di norma le due categorie di formazione e istruzione professionali infatti non vengono nettamente distinte in altre realtà nazionali e anche in Italia per lungo tempo sono usate indifferentemente come sinonimi, distinguendosi dall'apprendistato vero e proprio. Tuttavia, in Italia l'istruzione professionale - nel periodo dagli anni '10 agli anni '30 del XX secolo - si distacca per gradi, sul piano istituzionale e organizzativo, da quei circuiti locali o corporativi che la avevano accomunata alla formazione professionale ancora nel passaggio di secolo. A partire dall'età giolittiana e poi con il fascismo, di fronte ai primi passi dell'industrializzazione italiana, assistiamo - pur fra ambiguità e ripensamenti - a una sorta di assorbimento progressivo dell'istruzione professionale nella sfera di influenza dello Stato centrale (una delle forme assunte dal «central involvment» novecentesco) e della sua azione di regolazione sociale.

Con il fascismo, fra il 1928 e il 1938, l'istruzione professionale diviene sempre più scuola e, così, universalizzandosi si distacca dalla accentuata specificità della formazione professionale e a maggior ragione dell'apprendistato (cfr. tab. 1 in appendice). In questo processo - dal punto di vista del credenzialismo sul mercato del lavoro - l'istruzione professionale si avvicina minoritariamente all'istruzione tecnica, campo proprio di una professionalizzazione del lavoro più precisa, netta, a livello nazionale e come tale garantita direttamente dallo Stato fin dall'unità italiana. Definisce cioè qualifiche esecutive più elevate del lavoro generico e meglio statuite della formazione professionale, che si collocano però al di sotto delle figure tecniche intermedie. Questo processo distintivo è lento e pieno di ambiguità anche terminologiche, se ancora nel secondo dopoguerra la Costituzione repubblicana del 1948 - nel prevedere l'autonomia regionale - affida ai nuovi livelli istituzionali di governo territoriale, le regioni, la competenza diretta nel campo dell'«istruzione artigiana e professionale» (art. 117). La carta intende però circoscrivere così solo la formazione professionale extra-scolastica e non gli istituti professionali che dalla fine degli anni '20 sono ormai entrati definitivamente nell'orbita dell'azione statale e della pubblica istruzione.

L'istruzione tecnica, inferiore e superiore, pur segnata anch'essa da travagliate vicende normative e regolamentari soprattutto negli anni '20-'30 a seguito della riforma fascista del ministro Giovanni Gentile, mantiene sempre la sua originaria caratterizzazione scolastica ancorata all'educazione nazionale, salvo una breve parentesi negli anni '20. Essa si configura come una sorta di camera di compensazione all'interno della logica duale fortemente divaricata del sistema formativo italiano, sul piano sociale e culturale, una polarizzazione formativa che è per altro tipica di molti paesi europei nella prima parte del ' 900 di fronte all'industrializzazione. Da una parte, l'istruzione secondaria di carattere generale e astratta, accademico-liceale, che sola conduce all'università e in cui il modello gentiliano privilegia l'istruzione classica; dall'altra, la formazione direttamente addestrativa, scolastica e extrascolastica, che dà accesso, in tempi brevi, al lavoro esecutivo e manuale qualificato e semiqualificato; l'istruzione secondaria tecnica si colloca nel mezzo, è culturalmente subordinata all'istruzione generale ma comunque si situa in posizione superiore, in termini di status e di 
funzioni unitariamente definite, al macrocosmo disarticolato dell'istruzione e soprattutto della formazione professionali.

\section{Una distinzione resistente nel tempo}

Benché la Costituzione repubblicana - come già detto - prevedesse nel 1948 l'istituzione delle regioni e, in quel contesto di autonomia crescente del governo locale, prevedesse di affidare ad esse le competenze in materia di formazione professionale, in realtà il sistema di governo regionale sarà effettivamente attivato completamente solo nel 1970. Il processo di trasferimento alle regioni dei percorsi professionalizzanti formativi e addestrativi extra-scolastici si avvia con il DPR 10/1972. Il percorso normativo e organizzativo della regionalizzazione in materia sarà completato solo dalla L. 845/1978, che permetterà un primo raccordo con l'apprendistato (cfr. tab. 1 in appendice). Solo nei primi anni '80 e a trent'anni dalla Costituzione repubblicana, dunque, prenderanno davvero il via sia una politica regionale di programmazione in questo campo sia la definizione di sistemi di relazioni sindacali a questa scala intermedia fra Stato nazionale e governo locale. Solo allora, inoltre, compariranno sistematicamente altri attori istituzionali e sociali sulla scena, grazie ad un'attenzione nuova e crescente alla formazione delle risorse umane e al lifelong learning, che affiancheranno gli enti di emanazione sindacale, gli antichi circuiti assistenziali e soprattutto sostituiranno le strutture corporative ereditate dal fascismo, soppresse solo nel 1978. La dimensione locale, in Italia, resta in ogni caso predominante benché ridefinita all'interno della pianificazione a scala regionale e successivamente in relazione con le politiche sociali e del lavoro nazionali e poi comunitarie a livello europeo fra gli anni ' 80 e '90.

La partizione storica che distingue istruzione e formazione professionali, malgrado tutti i cambiamenti istituzionali, sociali ed economici del tumultuoso dopoguerra, regge dunque fino ad anni recenti, ben oltre la «grande trasformazione» della società industriale stessa. Nei primi anni successivi alla regionalizzazione, anzi essa amplifica inevitabilmente la divaricazione fra l'istruzione professionale considerata come scuola professionale statale e la formazione professionale regionale intesa come esperienza rigorosamente extra-scolastica (ma non necessariamente on the real job quale l'apprendistato). Negli anni '90, tuttavia emergono strategie sistemiche sempre più tendenti al coordinamento e all'integrazione all'interno della logica europea, mostrando una convergenza che avvicina l'Italia ad altre esperienze comunitarie.

Qualcosa sta oggi cambiando dopo la riforma organica dell'istruzione secondaria prevista dalla legge Moratti (L. 53/2003), che regolamenta l'alternanza scuola-lavoro (art. 4), assoluta novità per il sistema formativo italiano: da una parte, essa introduce il tirocinio esterno e professionalizzante accanto allo studio teorico o alla pratica dei laboratori intra monia; dall'altra, introduce il coordinamento, nella formazione e istruzione professionali, fra i due canali separatisi fin dagli anni '30, attraverso il nuovo obbligo formativo a 18 anni, previsto per la prima volta dalla L. 144/1999 (art. 68), da assolvere all'interno del sistema unitario dell' istruzione e formazione professionali, individuato sempre dalla L. 53/2003 (art. 2, commi d e h).

Un quadro normativo e regolamentare così articolato e complesso, per di più sostanzialmente stabile nel tempo fino ad anni recenti, ha inevitabilmente condizionato le modalità di regolazione delle relazioni sindacali in questo campo. L'eccessiva frammentazione e specificità delle esperienze formative e la frequente particolarità locale o corporativa delle modalità di intervento hanno impedito per lungo tempo che i soggetti sociali si interessassero sistematicamente alla questione e secondo prospettive non occasionali. Ed è questa una delle eredità più pesanti del fascismo, cui i primi interventi 
repubblicani, fra il 1947 e il 1949, orientati all'educazione popolare, all'alfabetizzazione, alla lotta alla disoccupazione, offrono solo un timido palliativo sul piano della professionalizzazione (tab. 1 in appendice). D'altro canto, il processo di assorbimento da parte dello Stato dell'istruzione professionale, avviato negli anni ' 30 e non messo in discussione dalla regionalizzazione degli anni '70, comporta una sostanziale delega alla pubblica istruzione di questa materia da parte degli attori sociali, mentre conferma la marginalità e secondarietà della formazione professionale, di nuovo rinviata ai circuiti locali e periferici nella messa in pratica operativa dell'attività formativa.

\section{Le relazioni sindacali fra locale e nazionale}

Confindustria, la principale organizzazione di rappresentanza dei datori di lavoro privati, organizza il suo primo convegno pubblico su questi temi solo nel 1959. Le organizzazioni sindacali, soprattutto la CGIL, per lungo tempo rinviano all'alfabetizzazione primaria la soluzione della questione, tenuto conto che ancora agli inizi degli anni ' $50 \mathrm{i}$ tre quarti dei ragazzi in età dell'obbligo scolastico non concludevano la scuola media inferiore, compresa la scuola di avviamento, e che quindi il problema di proseguire eventualmente nell'istruzione e formazione professionali era del tutto virtuale. Nelle interviste e nelle analisi legate alle prime indagini parlamentari dell'Italia repubblicana sulla questione sociale (quelle sulla miseria e sulla disoccupazione del 1953, quella sulle condizioni di lavoro del 1959), la formazione professionale risulta così ancora del tutto secondaria o assente nell'attenzione degli attori sociali e, spesso, anche degli specialisti. In fondo, in quegli anni l'Italia è un paese in cui l'impatto sociale della produzione industriale si sta ancora affermando e in cui invece i percorsi dell'alfabetizzazione, soprattutto nelle campagne e al Sud, sono sempre nettamente ritardati rispetto alle altre realtà europee.

Per il sindacato maggioritario, per tutti gli anni '50, la priorità è scolarizzare, alfabetizzare e istruire il popolo prima ancora che professionalizzarlo. In ogni caso, la CGIL punta sull'apprendistato in impresa, per sua natura in teoria più funzionale all'evoluzione sociale di un paese ancora percepito - erroneamente - come arretrato. La promulgazione della nuova legge nel 1955 arriva paradossalmente quando l'istituto dell'apprendistato sta declinando vistosamente insieme alle prospettive di « carriera operaia », almeno nella grande produzione di serie. Viceversa, proprio nel corso degli anni '50, la trasformazione industriale, la piena affermazione di nuovi modelli organizzativi (lo scientific management) e di classificazione del lavoro (la job evaluation), la penetrazione massiccia del taylorfordismo in alcuni settori produttivi di punta, giustificano lo spostamento definitivo all'esterno dell'impresa, in chiave compensativa, della formazione e dell'addestramento lavorativi, senza che però il sindacato sia preparato ad una prospettiva cooperativa sulla formazione professionale.

Fino ai governi del Centro-sinistra degli anni '60, la questione non viene sostanzialmente affrontata dal principale sindacato, la CGIL, benché la contemporanea crisi di rappresentanza nelle fabbriche apra un lacerante dibattito sulle innovazioni tecnologiche e organizzative e sulle modalità nuove del lavoro industriale che mettono in discussione le forme storiche della classificazione e della qualificazione operaia. In contrapposizione alla CGIL, questo tema comincia invece ad essere oggetto delle relazioni sindacali nell'industria pubblica (chimica e siderurgica) e trova la disponibilità negoziale delle altre due confederazioni sindacali, quella cattolica e quella riformista.

Il carattere fortemente centralizzato delle relazioni industriali e della contrattazione, dagli anni '50 fino alla seconda metà degli anni '60, in ogni caso penalizza fortemente la possibilità che il tema della formazione professionale rientri nel campo della negoziazione, vista la sua dispersione. A parte i rituali riferimenti all'apprendistato, l'assenza di 
contrattazione decentrata fino alla prima metà degli anni '60 evidenzia, fra le altre cose, la sostanziale disattenzione per questo tema, a parte qualche forma di sostegno assistenziale alla scolarizzazione sia dei minori che degli adulti. In particolare il contratto nazionale dei metalmeccanici e metallurgici è silente su questi temi fino al 1968. Una svolta reale, per quanto provvisoria, si ha solo dopo la rottura del 1969 (il cosiddetto « Autunno caldo »).

A fronte della fase di più alta conflittualità operaia del dopoguerra, della contestazione dei rapporti di forza in azienda e della delegittimazione dell'organizzazione statuita del lavoro, fra anni '60 e '70 si sviluppa una potente attività negoziale decentrata a livello di impresa che investe una pluralità di temi storicamente marginali, fra cui anche le questioni formative e del recupero scolastico, assai meno quelle della professionalizzazione. I contratti nazionali dell'industria nel 1973-'74 (meccanici, chimici tessili), per primi, ottengono due nuovi istituti - l'inquadramento unico operai-impiegati (classificazione unica) e il monteore retribuito per il diritto allo studio (le cosiddette «150 ore ») - che ruotano ambedue attorno alle opportunità di mobilità professionale, orizzontale e verticale, centrate sull'idea di «polivalenza » e di «professionalità » e non più sulla distinzione fra professione (diploma) e mestiere (qualifica).

Le difficoltà segnalate fin dagli anni '60 si confermano pure nella seconda metà degli anni '70, quelli della grande crisi economica e della trasformazione incipiente della società industriale, seguita alla cesura politica e sociale del 1968-'69 e alla stagione contrattuale di metà decennio. Nella cultura sindacale, pur in presenza di un forte decentramento contrattuale almeno nelle grandi imprese, resta la polarizzazione fra formazione generale e prospettive professionalizzanti e addestrative al lavoro industriale. Il sindacato non riesce a leggere in una chiave nuova i problemi della mobilità sociale, benché l'organizzazione del lavoro e le aspettative individuali e collettive nei suoi confronti e nei confronti della formazione stiano cambiando. In particolare, l'iniziativa sindacale - sempre più in difficoltà per la crisi economica - non riesce a intervenire sul nesso istituzionale, che abbiamo già visto fragile, fra istruzione professionale scolastica, formazione e addestramento extrascolastici e apprendistato, tanto che l'azione contrattuale di quegli anni non coglie pienamente la novità della stessa regionalizzazione né utilizza in questa direzione le « 150 ore ». L'azione sindacale unitaria, in Italia, si limita in quegli anni a perseguire la tradizionale parola d'ordine della democratizzazione nelle opportunità formative, sostanzialmente delegando ancora la questione professionale a vecchi e nuovi sistemi istituzionali e amministrativi (scuola tecnica e professionale, formazione professionale regionale), però in una chiave che resta socialmente compensativa e poco attenta alle politiche attive del lavoro. Non è un caso che l'esperienza delle «150 ore » per il diritto allo studio perda parecchia spinta innovativa già alla fine del decennio e poi negli anni seguenti sposti il suo fulcro fuori dai settori industriali, verso i servizi e il pubblico impiego.

La situazione della contrattazione in materia di formazione professionale e di risorse umane non migliora negli anni '80-'90 (ma anche dopo), pur di fronte alla radicale trasformazione nel frattempo intervenuta a sconvolgere il sistema industriale. Neppure il pieno dispiegamento delle politiche regionali e comunitarie in materia di lifelong learning sposta i termini della questione. La difficile articolazione territoriale e aziendale della contrattazione decentrata ed in particolare la storica fragilità della negoziazione a livello di impresa impediscono che in realtà, in Italia, ci si occupi effettivamente di questo tema e quando questo avviene, riguarda prevalentemente le medie e grandi imprese oltre i 250 addetti, cioè la parte minoritaria del sistema. Nel complesso delle imprese italiane, i contratti aziendali che affrontano il tema della formazione negli ultimi venti anni del ' 900 si collocano su percentuali irrisorie (una media del $6 \%$ sul totale) e spesso il riferimento è puramente rituale e routinario. Nello stesso periodo e praticamente fino ad oggi, però, niente di 
sostanziale interviene a modificare una struttura dell'istruzione tecnica e professionale che resta quella affermatasi nel secondo dopoguerra, mentre la formazione professionale resta di fatto accessoria e poco incisiva malgrado la regionalizzazione e le crescenti risorse disponibili.

\section{Alcune osservazioni conclusive su continuità e cesure}

Come già detto all'inizio, il sistema formativo italiano, storicamente, ha sempre privilegiato la formazione generale, in particolare umanistica, a scapito di quella scientifica e tecnica e, a maggior ragione, di quella professionale. Ciò non toglie che vi siano stati storicamente passaggi decisivi non solo nel dibattito culturale e pedagogico (ad es. la discussione su scuola media, scuola tecnica e scuola popolare all'inizio del ' 900 , la discussione sulla scuola media unica e sulla riforma della scuola secondaria superiore negli anni '50-'60, il dibattito sulla riforma generale del sistema scolastico negli anni '70), ma anche nella dislocazione degli attori e nella definizione degli strumenti normativi e organizzativi, che segnano un'attività di riforma - per quanto ad ondate - in questo campo (cfr. tab. 1 in appendice).

I ministeri economici in età giolittiana intervengono in maniera sempre più evidente a razionalizzare per via amministrativa un campo d'azione sociale esploso alla periferia del sistema di governo locale, in cui le sottoculture politiche all'opposizione, quella cattolica e socialista, sperimentano nuovi modelli municipali di intervento per fronteggiare le questioni sollevate dalla prima industrializzazione di una parte del paese. Un passaggio decisivo si realizza, dopo la Grande guerra, con il regime fascista e il suo dirigismo corporativo. Al di là della parentesi accentuatamente umanistica della riforma Gentile, gli anni che vanno dal 1928 alla guerra sanciscono la separazione fra l'istruzione professionale come scuola e la formazione professionale come esperienza extra-scolastica, all'interno di una profonda riorganizzazione del settore che di fatto resiste fino al 1962, per quanto riguarda l'avviamento al lavoro post-elementare (secondaria inferiore), e fino alla regionalizzazione, per quanto riguarda l'istruzione tecnica e professionale di Stato (secondaria superiore). Quanto avviene nell'immediato dopoguerra repubblicano è poca cosa, ed è ampiamente soverchiato dalle profonde trasformazioni sociali e economiche che caratterizzano il passaggio alla condizione di moderna grande nazione industriale, fra anni ' 50 e ' 60 . Per fare solo un esempio, i primi corsi serali di istruzione tecnica per adulti lavoratori vengono attivati solo fra il 1964 e il 1966 (cfr. tab. 1 in appendice).

La cesura più rilevante del periodo repubblicano, prima della regionalizzazione, è significativamente costituita da un intervento propriamente di politica scolastica, l'istituzione della scuola media unica nel 1962, che - creando un percorso di istruzione generale comune fino al compimento dell'obbligo scolastico - porta all'abolizione della scuola secondaria inferiore di avviamento professionale al lavoro, garantendo finalmente una coerenza fra offerta formativa e adempimento dell'obbligo scolastico. Si apre così, grazie al maggior benessere diffuso, l'opportunità di proseguire gli studi oltre la soglia dell'obbligo scolastico, di cui si avvantaggia l'istruzione tecnica e professionale scolastica. Per il resto, assai poco cambia, fatto salvo che nel periodo dei governi di Centro-sinistra (anni '60), in una congiuntura politica più nettamente pro labour che in passato e in connessione con la scolarizzazione di massa incipiente, cresce l'investimento statale nella promozione del sistema di istruzione professionale statale e in alcuni settori della formazione professionale. E' significativo che la contrapposizione fra accesso alla cultura generale e addestramento continui comunque a polarizzare il dibattito in quegli anni. Essa costituirà 
anche il riferimento successivo, quando si porrà - rispetto alle tematiche formative - il problema di « un intervento consapevole sulla divisione del lavoro».

Questo approccio si ritrova sia nella sinistra politica che in quella sindacale e tende ad escludere o a rinviare, attraverso il modello dell'educazione politecnica, il tema della professionalizzazione nella formazione, come in genere tutte le questioni legate alla didattica. L'aspirazione alla « polivalenza» (sia formativa che professionale), connessa alla categoria emergente di «professionalità », rinvia la questione di nuovo alla scuola e non riesce a ricomprendere pienamente all'interno delle strategie sindacali la formazione professionale del lavoro industriale.

Il 1969, l'anno della rivolta operaia, costituisce in questo campo dell'azione sindacale, come per altri, un vero spartiacque e apre le porte alla regionalizzazione del sistema istituzionale degli anni ' 70 e alla piena affermazione dell'idea di diritto allo studio contrapposta all'assistenza scolastica. Ribaltandosi momentaneamente i rapporti di forza nell'impresa e venendo contestata una struttura della riproduzione sociale generale che condiziona le aspettative individuali, emerge allora quella che viene definita una vera e propria « rivendicazione formativa » che si collega alla contemporanea transizione dalla centralità sociale dell'insegnamento a quella dell'apprendimento, molto dibattuta in Italia anche sul piano pedagogico e didattico e di cui le " 150 ore » sono il frutto più importante. Ma la professionalizzazione dei percorsi formativi resta ai margini di questo dibattito ancora per molto tempo.

\section{Apêndice}

\section{Tab. 1. Evolução da formação e instrução profissionais}

\begin{tabular}{|c|c|}
\hline Âmbito de aplicação e denominação & Legislação e competências \\
\hline $\begin{array}{l}\text { Escola técnica (ensino profissionalizante) } \\
\text { Instituto técnico (ensino médio) }\end{array}$ & $\begin{array}{r}\text { L 3725/1859 (lei Casati) } \\
\text { MPI - Municípios } \\
\text { MPI - Províncias }\end{array}$ \\
\hline Escolas comerciais, industriais e de arte aplicada à indústria & $\begin{array}{r}L 414 / 1907 \\
\text { Financiamento por parte do MAIC }\end{array}$ \\
\hline $\begin{array}{l}\text { Escolas de artes e profissões qualificadas como Escolas } \\
\text { Régias (instrução profissional) }\end{array}$ & $\begin{array}{r}R D 187 / 1908 \\
\text { Controle e coordenação por parte do MAIC } \\
\end{array}$ \\
\hline $\begin{array}{l}\text { Escolas populares operárias para artes e profissões, } \\
\text { qualificadas como Escolas régias } \\
\text { (instrução de primeira formação profissional, especialização } \\
\text { para chefes operários, ensino técnico industrial, comercial, } \\
\text { etc.) }\end{array}$ & $\begin{array}{r}L 854 / 1912 \\
\text { Controle e coordenação por parte do MAIC - } \\
\text { Consórcios locais entre municípios, províncias, } \\
\text { camâras de comércio e entes morais }\end{array}$ \\
\hline Laboratórios-escola & RDL 2001/1918 \\
\hline $\begin{array}{l}\text { Reforma da instrução técnica } \\
\text { (agrimensura e comercial, desincorporação daquela } \\
\text { industrial) }\end{array}$ & $\begin{array}{r}R D \text { 1054/1923 } \\
\text { Os institutos técnicos industriais e agronômicos } \\
\text { passam do MPI ao MEN (até 1928) }\end{array}$ \\
\hline $\begin{array}{l}\text { Escolas complementares, escolas de ensino } \\
\text { profissionalizante, escolas de capacitação profissional } \\
\text { (ensino complementar pós-fundamental) }\end{array}$ & $\begin{array}{r}R D 2185 / 1923 \\
\text { Escolas médias de treinamento ao trabalho executivo e } \\
\text { manual (11-13 anos) - MEN }\end{array}$ \\
\hline $\begin{array}{l}\text { Escolas para o ensino industrial (para formar operários } \\
\text { profissionais, chefes de operários, técnicos de produção), } \\
\text { estações experimentais para a indústria (cofinanciadas pelas } \\
\text { empresas) }\end{array}$ & $\begin{array}{r}R D 2523 / 1923 \\
\text { Instrução técnico-profissional industrial } \\
\text { (ensino médio) } \\
\text { MEN }\end{array}$ \\
\hline $\begin{array}{l}\text { Cursos para operariado (trabalhadores empregados), cursos } \\
\text { de especialização técnica para operários (aperfeiçoamento), } \\
\text { cursos temporários para emigrantes }\end{array}$ & $\begin{array}{r}R D \text { 969/1924 } \\
\text { (estes cursos são ligados às escolas de ensino industrial } \\
\text { acima) } \\
\text { MEN }\end{array}$ \\
\hline $\begin{array}{l}\text { Institutos de instrução técnica e profissional, classificados } \\
\text { como Escolas régias } \\
\text { (escolas minerárias, institutos industriais, escolas de } \\
\text { treinamento e profissionalizantes, laboratórios-escola, escolas }\end{array}$ & $\begin{array}{r}\text { L 3230/1928 } \\
\text { Do MEN ao MPI } \\
\text { - Direção geral } \\
\text { para o ensino técnico }\end{array}$ \\
\hline
\end{tabular}




\begin{tabular}{|c|c|}
\hline $\begin{array}{l}\text { profissionais femininas, escolas e institutos agrários, escolas } \\
\text { e institutos comerciais) }\end{array}$ & \\
\hline Consórcios provinciais para a instrução técnica & L 7/1929 (sobrevivem até 1978) \\
\hline Escolas profissionalizantes & $\begin{array}{r}L 8 / 1929 \\
\text { Escolas complementares, escolas profissionalizantes e } \\
\text { profissionais (ex L 2185/1923) }\end{array}$ \\
\hline $\begin{array}{l}\text { Escola profissionalizante, successivamente de capacitação } \\
\text { profissional } \\
\text { (ensino fundamental: agrária, industrial e artesanal, } \\
\text { comercial) }\end{array}$ & $\begin{array}{r}R D L \text { 1379/1930 } \\
\text { Reorganização instrução } \\
\text { complementar pós-elementar } \\
\text { (sobrevive até a instituição do ensino médio único em } \\
1962 \text { ) } \\
\end{array}$ \\
\hline Âmbito de aplicação e denominação & Legislação e competências \\
\hline $\begin{array}{l}\text { Escolas de instrução técnica e profissional } \\
\text { (escola profissionalizante, escola técnica, escolas } \\
\text { profissionais femininas, escolas de magistério profissional } \\
\text { para a mulher, institutos técnicos), cursos para o } \\
\text { aperfeiçonamento do operariado (estes últimos não podem } \\
\text { ser Escolas Régias - MIC) }\end{array}$ & $\begin{array}{r}L 889 / 1931 \\
\text { Reorganização definitiva da instrução técnica e } \\
\text { profissional (fundamental e média) } \\
\text { MPI }\end{array}$ \\
\hline Comitê central para a instrução técnica & $L 82 / 1936$ \\
\hline $\begin{array}{l}\text { Aprendizagem na empresa } \\
\text { (só treinamento prático) }\end{array}$ & $\begin{array}{r}R D L 1906 / 1938 \\
\text { Contratação } \\
\end{array}$ \\
\hline $\begin{array}{l}\text { Cursos para a formação e o treinamento dos trabalhadores } \\
\text { (formação profissional) }\end{array}$ & $\begin{array}{r}R D \text { 1380/1938 } \\
\text { Coordenação do MIC }\end{array}$ \\
\hline $\begin{array}{l}\text { Institutos profissionais Estatais } \\
\text { (escolas profissionais ex L 889/1931) }\end{array}$ & $\begin{array}{r}\text { RDL 2038/1938 } \\
\text { (ensino médio) }\end{array}$ \\
\hline $\begin{array}{l}\text { Aprendizagem na empresa } \\
\text { (só treinamento prático) }\end{array}$ & $\begin{array}{r}\text { RD 262/1942, arts. 2131-2133 } \\
\text { (Código Civil) }\end{array}$ \\
\hline Escola popular de alfabetização para os adultos & $\begin{array}{r}D L C P S 1599 / 1947 \\
\text { MPI }\end{array}$ \\
\hline $\begin{array}{l}\text { Competências regionais em matéria de instrução profissional } \\
\text { e artesanal (formação profissional) }\end{array}$ & Constituição da República italiana (1948), art. 117 \\
\hline $\begin{array}{l}\text { Cursos de qualificação e requalificação profissional, cursos } \\
\text { para desempregados, cursos empresariais de requalificação, } \\
\text { cursos práticos } \\
\text { (formação profissional) }\end{array}$ & $\begin{array}{r}L 264 / 1949 \\
\text { Comissão central para o ensino profissionalizante e } \\
\text { para a assistência aos desempregados - } \\
\text { MLPS (modificada pela } L 456 / 1951)\end{array}$ \\
\hline $\begin{array}{l}\text { Aprendizagem na empresa } \\
\text { (treinamento prático+cursos complementares) }\end{array}$ & $\begin{array}{r}L \text { 25/1955 } \\
\text { (depois revisada pela } L 424 / 1968 \text { ) - contratação } \\
\end{array}$ \\
\hline $\begin{array}{l}\text { Centros de treinamento profissional (para meninos cor } \\
\text { de } 14 \text { anos) }\end{array}$ & $\begin{array}{r}\text { CM 1/1961 } \\
\text { MLPS } \\
\end{array}$ \\
\hline $\begin{array}{l}\text { Cursos noturnos para trabalhadores } \\
\text { (instrução técnica. para trabalhadores-estudantes) }\end{array}$ & $\begin{array}{r}\text { CM 147/1964 e CM 411 e 1760/1966 } \\
\text { MPLS }\end{array}$ \\
\hline Formação profissional dos menores trabalhadores & L 977/1967, art. 25 \\
\hline $\begin{array}{l}\text { Liberalização dos acessos universitários também para a } \\
\text { instrução profissional Estatal }\end{array}$ & $L 754 / 1969$ \\
\hline $\begin{array}{l}\text { Decreto delegação de transferência da formação profissional } \\
\text { extraescolar às regiões ordinárias } \\
\text { Lei-quadro nacional sobre a formação profissional regional e } \\
\text { aprendizagem }\end{array}$ & DPR 10/1972 \\
\hline Contrato de formação-trabalho (12 ou 24 meses) & $\begin{array}{r}L 863 / 1984 \\
\text { (sucessivamente modificado pela } L 451 / 1994) \\
\end{array}$ \\
\hline $\begin{array}{l}\text { Sistema unitário da formação e instrução profissional } \\
\text { (obrigação formativa até } 18 \text { anos) }\end{array}$ & $\begin{array}{r}L 53 / 2003, \text { art. } 2 \\
\text { (reforma Moratti) }\end{array}$ \\
\hline
\end{tabular}
Legenda: MAIC - Ministério de agricultura, indústria e comércio; MPI - Ministério da pública instrução; MEN - Ministério da economia nacional (1923-1929), depois MIC - Ministério das corporações; MLPS - Ministério do trabalho e da previdência social (desde 1946). 
Tab. 2. Evolução legislativa sobre a obrigação escolar e sobre a tutela do trabalho de menores

\begin{tabular}{|c|c|c|c|}
\hline \multicolumn{2}{|c|}{ Obrigação de instrução e obrigação escolar } & \multicolumn{2}{|c|}{ Tutela do trabalho dos menores ${ }^{69}$} \\
\hline $\begin{array}{l}\text { L 3725/1859 } \\
\text { (lei Casati) }\end{array}$ & $\begin{array}{l}\text { Obrigação genérica } \\
\text { de instrução até } 7 \text { anos } \\
\text { Ensino fundamental } \\
\text { em dois ciclos até } 9 \text { anos } \\
\text { (I-IV série) } \\
\end{array}$ & & \\
\hline $\begin{array}{l}\text { L 3961/1877 } \\
\text { (lei Coppino) }\end{array}$ & $\begin{array}{l}\text { Obrigação institucionalizada de } \\
\text { instrução até } 9 \text { anos } \\
\text { Ensino fundamental } \\
\text { em dois ciclos (I-IV série) }\end{array}$ & L 3657/1886 & $\begin{array}{r}\text { Idade mínima para trabalhar } \\
\text { a partir de } 9 \text { anos }\end{array}$ \\
\hline $\begin{array}{l}\text { L 407/1904 } \\
\text { (lei Orlando) }\end{array}$ & $\begin{array}{l}\text { Obrigação de instrução escolar até } 12 \\
\text { anos } \\
\text { Ensino fundamental } \\
\text { em dois ciclos (I-IV série) } \\
\text { Ensino fundamental } \\
\text { ou dois anos adicionais de "escola } \\
\text { popular" (V-VI série) }\end{array}$ & $L 242 / 1902$ & $\begin{array}{r}\text { Idade mínima para trabalhar } \\
\text { a partir de } 12 \text { anos }\end{array}$ \\
\hline $\begin{array}{l}R D \text { 3126/1923 } \\
\text { (reforma Gentile) }\end{array}$ & $\begin{array}{l}\text { Obrigação de instrução escolar até } 14 \\
\text { anos } \\
\text { Ensino fundamental } \\
\text { em dois ciclos (I-V série) }\end{array}$ & & \\
\hline $\begin{array}{l}R D 2185 / 1923 \\
\text { (reforma Gentile) }\end{array}$ & $\begin{array}{l}\text { Ensino fundamental } \\
\text { ou escolas complementares pós- } \\
\text { fundamental e profissionalizante } \\
\text { (I-III série) }\end{array}$ & $\begin{array}{l}L 653 / 1934 \\
R D L 1906 / 1938\end{array}$ & $\begin{array}{r}\text { Idade mínima para } \\
\text { trabalhar a partir de } 14 \\
\text { anos } \\
\text { Aprendizagem } \\
\text { a partir de } 14 \text { anos }\end{array}$ \\
\hline $\begin{array}{l}\text { Constituição repúblicana } \\
\text { (1948), art. } 34 \\
\text { L 1859/1962 }\end{array}$ & $\begin{array}{l}\text { Confirmação da obrigação escolar até } \\
14 \text { anos } \\
\text { Instituição Ensino fundamental } \\
\text { único (I-III série) } \\
\text { (abolição escolas profissionalizantes) }\end{array}$ & $\begin{array}{l}\text { L 25/1955 } \\
\text { L 1325/1961 } \\
\text { L 977/1967 }\end{array}$ & $\begin{array}{r}\text { Aprendizagem (faixa etária } \\
14-18 \text { anos) } \\
\text { Idade mínima para trabalhar } \\
\text { a partir de } 14 \text { anos } \\
\text { Elimina todas as exceções } \\
\text { para o trabalho de menores } \\
\text { rural e familiar }\end{array}$ \\
\hline $\begin{array}{l}L \text { 9/1999 } \\
\text { (reforma Berlinguer) } \\
L 144 / 1999\end{array}$ & $\begin{array}{l}\text { Obrigação escolar até } 15 \text { anos } \\
\text { Obrigação formativa até } 18 \text { anos }\end{array}$ & $\begin{array}{l}\text { L 196/1997 } \\
\text { DDL 345/1999 }\end{array}$ & $\begin{array}{r}\text { Aprendizagem (faixa etária } \\
16-24 \text { anni) } \\
\text { Atuação diretiva } \\
\text { comunitária 94/33/CE }\end{array}$ \\
\hline $\begin{array}{l}\text { L 53/2003 } \\
\text { (reforma Moratti) }\end{array}$ & $\begin{array}{l}\text { Obrigação escolar até } 14 \text { anos e } \\
\text { obrigação formativa até } 18 \text { anos }\end{array}$ & & \\
\hline
\end{tabular}

\section{Referências}

AMATORI, F. L'Italia. Il tormentato sviluppo delle capacità organizzative tra Stato e famiglie. In. CHANDLER JR., A.D; AMATORI, F; HIKINO, T. (a cura di). Grande impresa e ricchezza delle nazioni, 1880-1990, Bologna, il Mulino, 1999.

AMBROSOLI, L. La scuola in Italia dal dopoguerra ad oggi, Bologna, il Mulino, 1982. BALDACCI, M; CAMBI, F; DEGL'INNOCENTI, M; LACAITA, C. G. Il Centro-sinistra e la riforma della scuola media (1962), Manduria-Bari-Roma, Lacaita, 2004.

BENAVOT, A. The Rise and Decline of Vocational Education. Sociology of Education, $\mathrm{n}$. $56,1983$.

BENENATI, E. Cento anni di paternalismo aziendale. Annali della Fondazione G.G. Feltrinelli, vol. XXXIII, 1999.

BONDIOLI, A. Formazione e professionalità, Roma, ESI, 1980.

BRINT, S. Schools and Societies, Stanford, Stanford U.P., 2006. 
CAUSARANO, P. La enseñanza profesional entre sociedad e instituciones: una primera síntesis para Italia (hasta la Repubblica). In. CASTILLO, S; PIGENET, M; SOUBIRANPAILLET, F. (coord.). Estados y relaciones de trabajo en la Europa del siglo XX, Madrid, Ediciones Cinca-Fundación Largo Caballero, 2007.

CEREJA, S. La scuola e il mondo del lavoro. Problemi dell'istruzione tecnica e professionale. Annali della Fondazione G.G. Feltrinelli, vol. XX, 1979-80.

CERLESI, P. Azione sindacale e intervento sulle strutture extra-scolastiche della formazione professionale. Quaderni di Rassegna sindacale, n.5, 1964.

COLASANTO, M. Obiettivi delle politiche di formazione professionale e iniziativa sindacale in tre paesi CEE. Annali della Fondazione Pastore, vol. IX, 1980.

FADDA, S. Formazione professionale e sviluppo regionale in Italia. Annali della Fondazione Pastore, vol. X, 1981.

FONTANA, R. Ristrutturazione del lavoro e iniziativa sindacale, Milano, Angeli, 1981. GALFRÉ, M. Una riforma alla prova, Milano, Angeli, 2000.

GENOVESI, G. (a cura di). Cultura e istruzione tecnico-professionale in Italia tra ' 800 e ‘900, Ferrara, CIRSE, 1988.

GIUGNI, G. et al., Ascesa e crisi del riformismo in fabbrica, Bari, De Donato, 1976

GOSPEL, H. F. Industrial Training and Technological Innovation, London-New York, Routledge, 1991.

HAZON, F. Storia della formazione tecnica e professionale in Italia, Roma, Armando, 1991.

LACAITA, C. G. Istruzione e sviluppo industriale in Italia, 1859-1914, Firenze, GiuntiBarbera, 1973.

MAIFREDA, G. La disciplina del lavoro, Milano, Bruno Mondatori, 2007.

MALATESTA, M. (a cura di). Storia d'Italia. Annale n. 10. I professionisti, Torino, Einaudi, 1996.

MINISTERO DELLA PUBBLICA ISTRUZIONE (a cura di). La scuola italiana dal 1946 al 1953, Roma, IPS, 1953.

MOKYR, J. The Gifts of Athena, Princeton, Pinceton U.P., 2002.

MORCALDI, M. Le scuole industriali (1880-1930), Milano, Angeli, 2004.

NAVILLE, P. La formation professionnelle et l'école, Paris, PUF, 1948.

PAGE, E. C. Localism and Centralism in Europe, Oxford, Oxford U.P., 1991.

PIVATO, S. Movimento operaio e istruzione popolare nell'Italia liberale, Milano, Angeli, 1986.

QUEIROLO PALMAS, L. Le fabbriche della formazione, Torino, L'Harmattan Italia, 1996.

ROLLE, P. I paradossi del lavoro, Bari, Dedalo, 1983.

RUSCONI, M; SARACENO, C. Il lavoro dei bambini. In. MUSSO, S. (a cura di). Operai, Torino, Rosenberg \& Sellier, 2006.

SANTONI RUGIU, A. Breve storia dell'educazione artigiana, Roma, Carocci, 2008.

SAPELLI, G. (a cura di), Impresa e sindacato, Milano, Angeli, 1996.

SAPELLI, G. Comunità e mercato, Bologna, il Mulino, 1986.

SATTA, G. Sapere e saper fare, Rimini, Maggioli, 1984. 
SENNETT, R. The Craftsman, New Haven and London, Yale U.P., 2008.

SOLDANI, S. L'istruzione tecnica nell'Italia liberale (1861-1900). Studi storici, n. 1, 1981.

TOGNON, G. L'industria e le politiche per la formazione. Storia, problemi e prospettive della formazione professionale in Italia. L'industria, n. 4, 2002.

TOMASI, T. Idealismo e fascismo nella scuola italiana, Firenze, La Nuova Italia, 1969.

TOMASI, T. La scuola italiana dal 1870 ai giorni nostri, Roma, Editori Riuniti, 1967.

TOMASSINI, L. L'associazionismo operaio: aspetti e problemi del mutualismo nell'Italia liberale. Annali della Fondazione G.G. Feltrinelli, vol. XXXIII, 1999.

TONELLI, A. L'istruzione tecnica e professionale di Stato nelle strutture e nei programmi da Casati ai nostri giorni. Milano, Giuffré, 1964.

TURI, G. (a cura di). Libere professioni e fascismo, Milano, Angeli, 1994.

VASTA, M. Capitale umano e ricerca scientifica e tecnológica. In. AMATORI, F. et al. (a cura di), Storia d'Italia. Annale n. 15. L'industria, Torino, Einaudi, 1999.

VENTURA, S. La politica scolastica, Bologna, il Mulino, 1998.

VINCENT, D. The Rise of Mass Literacy, Cambridge, Polity Press, 2000.

ZANINELLI, S; TACCOLINI, M. (a cura di). Il lavoro come fattore produttivo e come risorsa nella storia economica italiana, Milano, Vita \& Pensiero, 2002.

Notas ${ }^{1}$ Versão traduzida do ensaio "Lo Stato e le relazioni sindacali di fronte alla formazione professionale: il caso
italiano nel secondo dopoguerra". Nós, organizadores, optamos por disponibilizar à comunidade acadêmica
brasileira ambas as versões do texto, a tradução, em português, e a versão original, em italiano - que se encontra
a partir da $11^{\text {a }}$ página deste arquivo.
${ }^{2}$ Professor associado do Departamento de Ciências da Formação e Psicologia da Università degli Studi di
Firenze (Itália). Email: pietro.causarano @ unifi.it
${ }^{3}$ Contatos:rizzottotraducoes @ gmail.com / www.rizzottotraducoes.com.br
${ }^{4}$ H.F. Gospel (ed.), Industrial Training and Technological Innovation, London-New York, Routledge, 1991.
Mais em geral, J. Mokyr, The Gifts of Athena, Princeton, Princeton U.P., 2002. Para a Itália, M. Vasta, «
Capitale umano e ricerca scientifica e tecnologica », em F. Amatori et al. (organizado por), Storia d'Italia.
Annale n. 15. L'industria, Torino, Einaudi, 1999, p. 1043-1124; S. Zaninelli e M. Taccolini (organizado por),
Il lavoro come fattore produttivo e come risorsa nella storia economica italiana, Milano, Vita \& Pensiero,
2002 .
${ }^{5}$ S. Brint, Schools and Societies, Stanford, Stanford U.P., 2006², p. 31-96.
${ }^{6}$ D. Vincent, The Rise of Mass Literacy, Cambridge, Polity Press, 2000.
${ }^{7}$ G. Tognon, « L'industria e le politiche per la formazione. Storia, problemi e prospettive della formazione
professionale in Italia », em L'industria, 2002, n. 4, p. 719-744.

${ }^{8}$ A. Benavot, «The Rise and Decline of Vocational Education », em Sociology of Education, 1983, n. 56, p. 63-76.

${ }^{9} \mathrm{M}$. Morcaldi, Le scuole industriali (1880-1930), Milano, Angeli, 2004.

${ }^{10} \mathrm{~A}$. Tonelli, L'istruzione tecnica e professionale di Stato nelle strutture e nei programmi da Casati ai nostri giorni. Milano, Giuffré, 1964; C.G. Lacaita, Istruzione e sviluppo industriale in Italia, 1859-1914, Firenze, Giunti-Barbera, 1973; S. Soldani, «L'istruzione tecnica nell'Italia liberale (1861-1900) », em Studi storici, 1981, n. 1, p. 79-117; M. Malatesta (organizado por), Storia d'Italia. Annale n. 10. I professionisti, Torino, Einaudi, 1996.

${ }^{11}$ F. Hazon F., Storia della formazione tecnica e professionale in Italia, Roma, Armando, 1991. 
${ }^{12} \mathrm{P}$. Causarano, «La enseñanza profesional entre sociedad e instituciones: una primera síntesis para Italia (hasta la Repubblica) », em S. Castillo, M. Pigenet, F. Soubiran-Paillet (coord.), Estados y relaciones de trabajo en la Europa del siglo XX, Madrid, Ediciones Cinca-Fundación Largo Caballero, 2007, p. 85-103.

${ }^{13} \mathrm{G}$. Tognon, «L'industria e le politiche per la formazione », op. cit., p. 737-739.

${ }^{14} \mathrm{Em}$ geral, sobre a atualidade deste debate em torno da ideia de que «fazer é pensar », R. Sennett, The Craftsman, New Haven and London, Yale U.P., 2008.

${ }^{15} \mathrm{G}$. Genovesi (organizado por), Cultura e istruzione tecnico-professionale in Italia tra ' 800 e '900, Ferrara, CIRSE, 1988.

${ }^{16} \mathrm{G}$. Turi (organizado por), Libere professioni e fascismo, Milano, Angeli, 1994.

${ }^{17}$ É o caso por ex. da figura de perito industrial, normatizada antes pelo art. 7, L. 1395/1923, e depois pelo RD 275/1929 para a inscrição no cadastro de profissional.

${ }^{18}$ G. Satta, Sapere e saper fare, Rimini, Maggioli, 1984.

${ }^{19}$ Sobre a distribuição diferenciada da instrução profissional e técnica, cfr. « La scuola secondaria superiore italiana negli anni Settanta », Annali della Pubblica Istruzione, vol. 4 (1978), p. 51-69.

${ }^{20}$ A dimensão média das empresas italianas, no inteiro pós-guerra, é de 10 empregados, enquanto 50-60\% dos operários trabalha em empresas com menos de 100 empregados, principalmente no centro e no noroeste; F. Amatori, «L'Italia. Il tormentato sviluppo delle capacità organizzative tra Stato e famiglie », em A.D. Chandler jr., F. Amatori e T. Hikino (organizado por), Grande impresa e ricchezza delle nazioni, 1880-1990, Bologna, il Mulino, 1999, p. 346

${ }^{21}$ O R. D. 1380/1938, ao instituir cursos de formação e aperfeiçoamento dos trabalhadores sob o patrocínio do Ministério das corporações, atua uma primeira tentativa de coordenação. Esta mediação administrativa, após a guerra e a democratização, é retomada pela L. 246/1949 que institui uma comissão ministerial, aberta às partes sociais.

${ }^{22}$ L. Tomassini, « L'associazionismo operaio: aspetti e problemi del mutualismo nell'Italia liberale», e E. Benenati, «Cento anni di paternalismo aziendale », em Annali della Fondazione G.G. Feltrinelli, vol. XXXIII (1999), p. 3-81. Para se ter uma ideia da difusão e também da dispersão destas instituições ainda na década de 60 do século XX, consultar a lista em Servizi Aziendali (organizada por) Guida pratica all'addestramento professionale, Roma, San Marco, 1962, p. 7-18: trata-se de 32 instituições nacionais de formação, 15 regionais com destacamentos provinciais, 84 locais credenciados junto aos ministérios econômicos; a lista não inclui a infinidade de insituições assistenciais ancoradas na tradição local e com áreas atendidas muito limitadas e específicas.

${ }^{23}$ M. Morcaldi, Le scuole industriali op. cit., primeira parte. Seu declínio depende principalmente da massificação e padronização da produção industrial; L. Queirolo Palmas, Le fabbriche della formazione, Torino, L'Harmattan Italia, 1996.

${ }^{24}$ A. Santoni Rugiu, Breve storia dell'educazione artigiana, Roma, Carocci, 2008.

${ }^{25}$ G. Maifreda, La disciplina del lavoro, Milano, Bruno Mondatori, 2007, p. 154-189.

${ }^{26}$ P. Naville, La formation professionnelle et l'école, Paris, PUF, 1948. O modelo clássico desta formalização crescente, na Europa, é constituído pela instrução profissional no « dual system » alemão; W.-D. Greinert, The «German System » of Vocational Education, Baden-Baden, Nomos Verlagsgesellschaft, 1994.

27 S. Cereja, «La scuola e il mondo del lavoro. Problemi dell'istruzione tecnica e professionale », em Annali della Fondazione G.G. Feltrinelli, vol. XX (1979-80), p. 51-90.

${ }_{28}$ M. Rusconi, C. Saraceno, « Il lavoro dei bambini », em S. Musso (organizado por), Operai, Torino, Rosenberg \& Sellier, 2006, p. 243-268.

${ }^{29}$ P. Causarano, « La enseñanza profesional », op. cit., p. 95-96.

${ }^{30}$ E.C. Page, Localism and Centralism in Europe, Oxford, Oxford U.P., 1991, p. 96-137.

${ }^{31}$ A lei Casati (L. 3725/1859), fundadora do sistema escolar da Itália unida, trata só da instrução técnica fundamental e média, confiando-a às autarquias locais (municípios e províncias), enquanto a instrução e a formação profissionais são completamente externas às instituições públicas e reenviadas às relações sociais e econômicas. Só na década de 80 do século XIX, o Ministério de Agricultura, Indústria e Comércio começa a se ocupar dela. A intervenção do Estado na coordenação da instrução profissional se torna cogente pela primeira vez, no âmbito financeiro e organizacional, entre 1907 e 1912, aviando a separação gradual da formação profissional (cfr. tab. $n^{\circ} 1$ em apêndice).

${ }^{32}$ A. Tonelli, L'istruzione tecnica e professionale op. cit., p. 89-98, 101-104. Em geral, M. Galfré, Una riforma A A 
${ }^{33}$ Em particular, contudo, é para sinalizar a desincorporação da seção industrial da instrução técnica, passada provisoriamente às dependências dos ministérios econômicos junto com a instrução profissional; só com o pleno desdobramento do regime fascista, mudado o clima cultural dentro do debate sobre o corporativismo (Carta do trabalho em 1927, Carta da escola em 1939), haverá uma reorganização na instrução técnica industrial e a volta à instrução pública (cfr. tab. $\mathrm{n}^{\circ} 1$ em apêndice); R. Gentili, Giuseppe Bottai e la riforma fascista della scuola, Firenze, La Nuova Italia, 1979, p. 41-44, 119-125, 129-131.

${ }^{34}$ T. Tomasi, Idealismo e fascismo nella scuola italiana, Firenze, La Nuova Italia, 1969.

${ }^{35}$ A. Scotto di Luzio, La scuola degli italiani, Bologna, il Mulino, 2007, p. 57-79, 176-181, 366-369. Considere-se que, contudo, na Itália a instrução técnica industrial dará acesso às faculdades universitárias não tecnológicas somente muito tarde, com a República, e que a liberalização definitiva dos acessos universitários ocorrerá somente em 1969 também para a instrução profissional Estadual (não para a formação profissional extraescolar).

${ }^{36}$ S. Fadda, «Formazione professionale e sviluppo regionale in Italia », em Annali della Fondazione Pastore, vol. X (1981), p. 27-66.

${ }^{37} \mathrm{Em} 2001$ resultam assim 1.548 centros regionais de formação profissional; G. Tognon, «L'industria e le politiche per la formazione», op. cit., p. 726.

${ }^{38} \mathrm{Ou}$ como, a partir da década de 80, o novo instituto dos contratos de formação-trabalho (L. 863/1984, depois modificado com L. 451/1994), mesmo conexo à articulação dos novos sistemas regionais da formação profissional.

39 «L'istruzione professionale in Italia nel decennio 1988-1998», Annali della Pubblica Istruzione, vol. 6768, 1994. Em geral, cfr. Y. Morvan (dir.), La formation tout au long de la vie, Rennes, PUR, 2006.

${ }^{40}$ « L'alternanza scuola-lavoro», Annali dell'istruzione, vol. L (2003-04), n. 5-6 e n. 1.

${ }^{41}$ Cfr. Ministero della pubblica istruzione (a cura di), La scuola italiana dal 1946 al 1953, Roma, IPS, 1953, em particular p. 45-48, 75-94. Contudo, estas experiências do imediato pós-guerra consolidam também os primeiros casos institucionalizados de cooperação entre organizações de representação dos interesses, se bem que no interior da mediação administrativa governamental, e o envolvimento das instituições previdenciárias nacionais no financiamento do treinamento profissional através de fundos adequados.

${ }^{42}$ I. Pisoni Cerlesi, «Azione sindacale e intervento sulle strutture extra-scolastiche della formazione professionale », in Quaderni di Rassegna sindacale, 1964, n. 5, p. 15-18

${ }^{43}$ Confindustria (por), L'istruzione e l'industria, Roma, Tip. Failli, 1959.

${ }^{44}$ S. Ventura, La politica scolastica, Bologna, il Mulino, 1998, p. 124. Ainda em 1969, somente um quarto dos operários completou a obrigação escolar; L. Balbo, G. Chiaretti, « Le classi subordinate nella scuola di massa », em Inchiesta, 1972, n. 6, p. 23-38. Afinal, na década de 50, só um adolescente a cada dez acessa a instrução média, inclusive a profissional; cfr. M. Vasta, « Capitale umano e ricerca scientifica e tecnologica », op. cit., p. 1054-1055.

${ }^{45}$ P. Causarano, La enseñanza profesional, op. cit., p. 97-100.

${ }^{46}$ A percentual de analfabetos totais é de $22 \%$ em 1931 e ainda de $12 \%$ em 1951; D. Marchesini, «Città e campagna nello specchio dell'analfabetismo (1921-1951) », em S. Soldani, G. Turi (organizado por), Fare gli italiani, Bologna, Il Mulino, 1993, vol. 2, p. 37.

${ }^{47}$ R. Fontana, Ristrutturazione del lavoro e iniziativa sindacale, Milano, Angeli, 1981, p. 77-86.

${ }^{48} \mathrm{P}$. Rolle, I paradossi del lavoro, Bari, Dedalo, 1983.

${ }^{49}$ Istituto Gramsci (organizado por), I lavoratori e il progresso tecnico, Roma, Editori Riuniti, 1956. Cfr. A. Accornero, Gli anni '50 in fabbrica, Bari, De Donato, 1973.

${ }^{50} \mathrm{G}$. Giugni et al., Ascesa e crisi del riformismo in fabbrica, Bari, De Donato, 1976, e G. Sapelli (organizado por), Impresa e sindacato, Milano, Angeli, 1996.

${ }^{51}$ Por ex., só os contratos dos trabalhadores na construção civil e dos gráficos, no pós-guerra, preveem escolas profissionais para o treinamento de gestão de igualdade de oportunidades; P.A. Varesi, « La contrattazione collettiva in materia di formazione professionale », em Annali della Fondazione Pastore, vol. XII (1983), em particular p. 111-123.

${ }^{52}$ A. Bondioli, Formazione e professionalità, Roma, ESI, 1980.

${ }^{53}$ Sobre as 150 horas, « Nuova domanda formativa del lavoratore metalmeccanico », dossier Formazione $e$ lavoro, 1973-74, n. 67-68 e n. 69-70. Cfr. também L. Dore, Fabbrica e scuola, Roma, ESI, 1974; L. Libertini, Tecnici impiegati operai, Roma, Editori Riuniti, 1974. 
${ }^{54}$ Considere-se o fenômeno dos trabalhadores-estudantes, em crescimento constante entre as décadas de 60 e 70, só em mínima parte colhido pela experiência contratual da década de 60; «Lavoratori-studenti », dossiê Formazione e lavoro, 1969, n. 38, e M. Isnenghi, « I lavoratori studenti tra integrazione e insubordinazione », em Problemi del socialismo, n.s., 1976, n. 44, p. 60-68.

55 « Regione e formazione professionale », dossiê em Formazione e lavoro, 1972, n. 52-53. As 150 horas terão grande extensão por toda a década de 70 , envolvendo centenas de milhares de operários em cursos e experiências formativas de cultura geral ou de reposição da obrigação escolar, além de formação sindical. As 150 horas, contudo, ao menos até tarde na década de 80, serão excluídas dos percursos de formação profissional, delegados às regiões; N. Delai, Tra scuola e lavoro, Venezia, Marsilio, 1977.

${ }^{56} \mathrm{M}$. Colasanto, « Obiettivi delle politiche di formazione professionale e iniziativa sindacale in tre paesi CEE », em Annali della Fondazione Pastore, vol. IX (1980), p. 91-109.

${ }^{57}$ P.A. Varesi, « La contrattazione collettiva in matéria di formazione professionale », op.cit., p. 123-130.

${ }^{58}$ Considere-se que os percentuais de empresas envolvidas na contratação territorial ou empresarial descentralizada são baixos, em média igual a um quarto do total e, prevalentemente, ainda concentradas entre as médio-grandes; F. Farinelli, S. Vaccaro, « La contrattazione della formazione e i Fondi interprofessionali », em R. Pettenello (organizado por), La formazione dei lavoratori, il sindacato e la contrattazione, Roma, Ediesse, 2006, p. 195-222. Confirmações sobre os atrasos italianos, em perspectiva comparada, têm em C. Pellegrini (organizado por), Analisi della politica contrattuale nel campo della formazione continua, Milano, Angeli-ISFOL, 1994.

${ }^{59}$ T. Tomasi, La scuola italiana dal 1870 ai giorni nostri, Roma, Editori Riuniti, 1967, p. 139-149, 163-165, 171-183; L. Ambrosoli, La scuola in Italia dal dopoguerra ad oggi, Bologna, il Mulino, 1982, p. 55 e ss.; M. Baldacci, F. Cambi, M. Degl'Innocenti, C.G. Lacaita, Il Centro-sinistra e la riforma della scuola media (1962), Manduria-Bari-Roma, Lacaita, 2004.

${ }^{60}$ S. Pivato, Movimento operaio e istruzione popolare nell'Italia liberale, Milano, Angeli, 1986; G. Sapelli, Comunità e mercato, Bologna, il Mulino, 1986.

${ }^{61}$ Não a formação profissional extraescolar que, de fato, logo após o ensino fundamental único e a abolição do ensino profissionalizante, vê cair as inscrições aos cursos de 280.000 em 1961-62 para 159.000 em 1962-63. O nível dos anos 50 é alcançado de novo somente em 1970-71 com 275.000 inscritos. Nos mesmos anos, por sua vez, há uma verdadeira explosão da instrução técnica e profissional: a instrução técnica passa de 360.000 inscritos em 1961-62 para 716.000 em 1971-72; a instrução profissional estatal de 124.000 para 271.000. Cfr. R. Emma, A. Sarcina, La formazione professionale, Roma, ESI, 1975, p. 220, 224.

${ }^{62}$ É um dos grandes temas do debate cultural e civil daqueles anos; cfr. INAPLI, CENSIS (organizado por), I problemi attuali della formazione professionale, Roma, INAPLI, 1966, p. 19-71.

${ }^{63} \mathrm{~F}$. Ciafaloni, « Per un intervento consapevole sulla divisione del lavoro », em Inchiesta, 1972, n. 7, p. 18-31.

${ }^{64}$ L. Lombardo Radice, «Scuola e lotta di classe », em Riforma della scuola, 1969, n. 1, p. 3-5; S. Garavini, « La qualità della forza-lavoro », ivi, n. 12, p. 11-15.

${ }^{65}$ A. Santoni Rugiu, «Utopia educativa e divisione del lavoro », em Scuola e Città, 1973, n. 11, p. 535-542.

${ }^{66}$ «Cultura e professionalità », dossiê em Formazione e lavoro, 1970, n. 42.

${ }^{67}$ Emblemática a posição de um importante dirigente sindical, que por um lado observa a reciprocidade entre credencialísmo escolar e sistema histórico das qualificações de trabalho, e, do outro, reduz a solução à extensão dos percursos formativos de cultura geral; S. Garavini, «Per un nuovo rapporto tra i valori della scuola e i valori professionali del lavoro », em Quaderni di Rassegna sindacale, 1964, n. 5, p. 5-11; Id., « Il rapporto scuola-produzione », em Scuola e Città, 1965, n. 6-7, p. 390-392.

${ }^{68}$ M. Carboni, «La rivendicazione formativa », em Formazione e lavoro, 1969, n. 40, p. II-IV, introdução ao dossiê « Scuola e movimento operaio ». Cfr. também « Esplode l'apprendimento », ivi, 1971, n. 47.

${ }^{69}$ Até 1967, a legislação de tutela do trabalho dos menores, combinada com a feminina, prevê várias derrogações aos limites sancionados (principalmente em favor do trabalho doméstico e da relação de trabalho familiar artesanal e rural); além disso, com frequência os limites de idade e de horas para os menores variam de acordo com os setores e do peso do trabalho; P. Causarano, « La enseñanza profesional », op. cit., p. 9395.

Recebido: $\quad$ março-15 abrovado: $\quad$ abril-15 